\title{
FEASIBILITY STUDY FOR AUTOMATING THE ANALYTICAL LABORATORIES OF THE CHEMISTRY BRANCH, NATIONAL ENFORCEMENT INVESTIGATION CENTER, ENVIRONMENTAL PROTECTION AGENCY
}

\author{
W. F. Morris \\ E. R. Fisher \\ G. W. Barton, Jr.
}

June 1, 1978

Work performed under the auspices of the U.S. Department of Energy by the UCLLL under contract number W-7405-ENG-48.

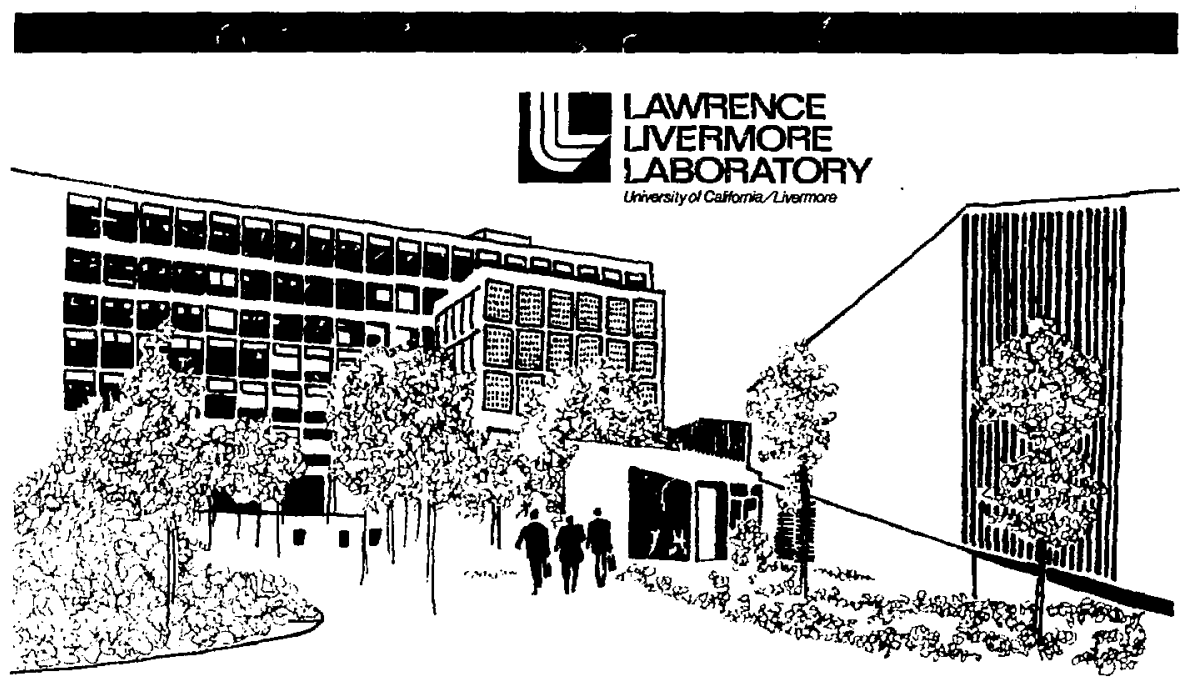




\title{
近 \\ LAWRENCE LIVERMORE LABORATORY \\ University of Cahtornia, Livermore, Calitomia, 94550
}

\section{FEASIBILITY STUDY FOR AUTOMATING THE ANALYTICAL LABORATORIES OF THE CHEMISTRY BRANCH, NATIONAL ENFORCEMENT INVESTIGATION CENTER, ENVIRONMENTAL PROTECTION AGENCY}

\author{
W. F. Morris \\ E. R. Fisher \\ G. W. Barton, $\mathbf{J}_{\mathbf{r}}$.
}

MS. date: June 1, 1978

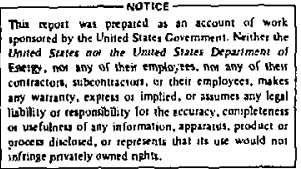




\section{CONTENTS}

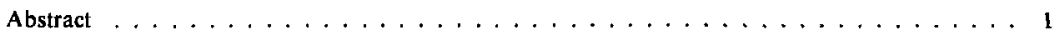

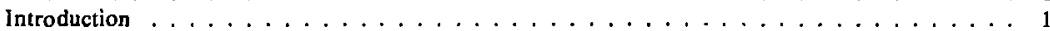

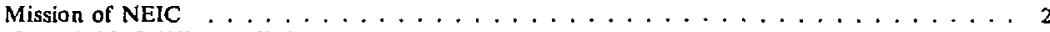

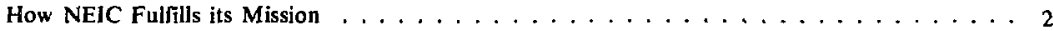

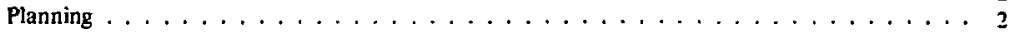

Preliminary Reconnaissance $\ldots \ldots \ldots \ldots \ldots \ldots \ldots$

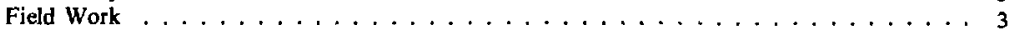

Laboratory Work, Data, and Reports . . . . . . . . . . . . . . . . . 3

Function of the Chemistry Branch in a Typical Survey $\ldots \ldots \ldots \ldots$

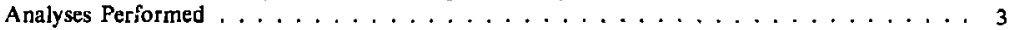

Division of Responsibility ......................... 3

Information and Data Flow, Chain of Custody, Records, and Reports . . . . . . . . . . 4

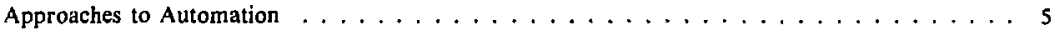

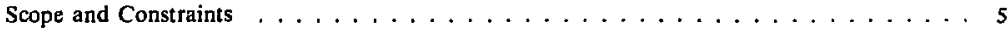

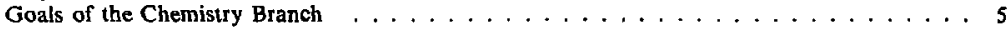

Candidate Instruments for Automation . . . . . . . . . . . . . 6

The Study Plan, Job Scheduling, Coordination, and Sample $\ldots \ldots \ldots \ldots \ldots$

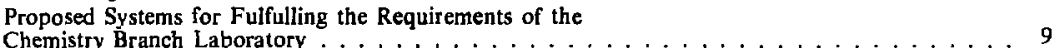

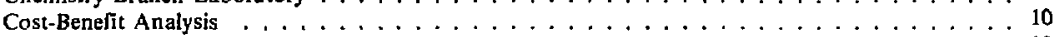

Preliminary Remarks ........................... 10

Basis for the Analysis ........................... 10

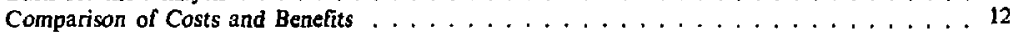

Costs and Benefits Relative to Payout Time and

System Life . . . . . . . . . . . . . . . . . . . . . . . . . . . . 13

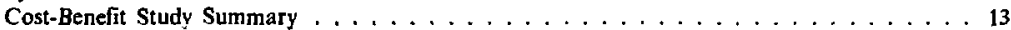

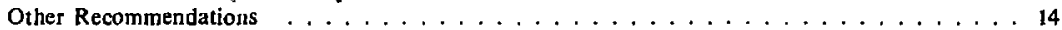

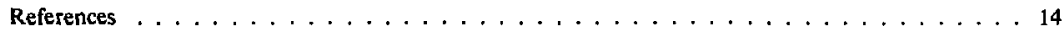

Appendix A: Proposed Optional Automation Systems . . . . . . . . . . . . . 15

Appendix B: One-Time Costs for the Five Proposed Computer

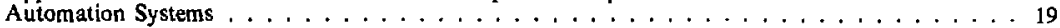

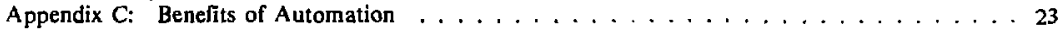

Appendix D: Description and Breakdown of Added Operating Costs as a

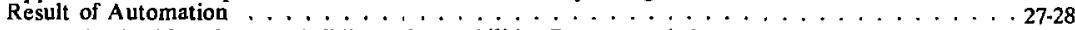

Appendix E: New Personnel Skills and Capabilities Recommended

for the Automated Laboratory . . . . . . . . . . . . . . . . . . . . . . . . . 29 


\section{FEASIBILITY STUDY FOR AUTOMATING THE ANALYTICAL LABORATORIES OF THE CHEMISTRY BRANCH, NATIONAL ENFORCEMENT INVESTIGATION CENTER, ENVIRONMENTAL PROTECTION AGENCY}

\section{ABSTRACT}

This report explores the feasibility of automating the analytical laboratories of the Chemistry Branch of the National Enforcement Investigation Center, Environmental Protection Agency, Denver, Colorado. We define the goals of the chemistry laboratory and describe instrumental methods and other tasks to be automated. We propose five optional automation systems to meet these goals and evaluate the options in terms of cost effectiveness and other specified criteria.

\section{INTRODUCTION}

The objectives of this study are to establish a comprehensive definition of the current and future automation requirements of the chemistry branch of the National Enforciement Investigation Center (NEIC) and to present a cost/benefit analysis of systems that will fulfill these requirements. These objectives coincide with certain general objectives of the EPA. One of the primary objectives of the EPA is to improve the reliability of data and reports generated by all EPA laboratories. To realize this, EPA is actively promoting the use of more quality assurance checks and the adoption of optimized standard procedures. Because these endeavors add to the workload of the laboratories, automation techniques are being promoted to handle the workload and reduce the incidence of human errors.

Since 1973, the Envitonmental Research Center (ERC) in Cincinnati and the Lawrence Ljvermore Laboratory (LLL) have conducted a joint project ${ }^{1}$ to specify, design, and install three laboratory automation systems. The systems are located in the Environmental Monitoring and Support Laboratory (EMSL) and the Municipal Environmental Research Laboratory (MERL), both located in Cincinnati, Ohio, and the Region V Surveillance and Analysis laboratory in Chicago.

These systems have been designed with EPA objectives in mind. At the same time, they have evolved into a powerful common system design that meets the special needs of water analysis taboratories. This common design represents a substantial investment $(\$ 500,000)$ by EPA in terms of specifications, fundamental systems design, hardware interface design, and software. It should, therefore, receive primary consideration as a proposer system for automation of a candidate laboratory such as NEIC.

We have proposed five optional automation systems. We find that two of them are economically feasible, and use the standard EPA laboratory automation system with virtually no modifications of currently available EPA software and hardware interfaces that are applicable to NEIC needs. The two options also propose a communications link with a Sample File Control (SFC) system that is now being developed by EPA for use throughout the agency. We have found that the costs of automation can be justified only if the benefits are derived from automation of sample management activities as well as from automation of laboratory instrument procedures.

In addition, we recommend that analyses performed in the field be considered for future automation or inclusion in the current system. Of specific concern are solids determinations by electronic balance, and lithium determinations by atomic absorption spectrophotometry. The latter are used for stream-flow calculations in the field. 


\section{MISSION OF NEIC}

The NEIC is a field operations unit of the EPA that supplies technical information to the Office of Enforcement of the EPA in Washington, D.C. It is required to respond quickly and reliably to emergencies, to aid the regional offices and other EPA units in the field, and to provide expert advice and consultation for municipal, industrial, and agricultural pollution control.

The NEIC mission is coordinated through two offices supervised by the director: the Office of Planning and Management, and the Office of Technical Programs. There are six branches under the Office of Technical Programs: chemistry, biology, field operations, process control, technical services, and air technology. These branches conduct the technical mission of the NEIC relative to field and laboratory studies, and also receive legal advice from the enforcement specialist in the director's office as well as varied support and data processing aid from the Office of Planning and Management.

The NEIC is concerned principally with water and air pollution. Water pollution activities include case preparation studies, special compliance monitoring surveys, and verification of permit conditions and requirements of the National Pollutant Discharge Elimination System (NPDES). Air pollution functions involve State Implementation Plan (SIP) inspections, source testing survey, and special pollution studies.

For the fiscal year 1977 the effort of NEIC was divided among the following activities:

- Water enforcement studies, mainly case preparations (44\%).

- Stationary source studies; for example, power-plant stack monitoring $(33 \%)$.

- Mobile source studies (8\%).

- Pesticide en forcement studies (12\%).

- General and miscellaneous studies (3\%).

\section{HOW NEIC FULFILLS ITS MISSION}

Although the NEIC participates in a wide variety of investigations, certain procedures are common to every investigation and require the cooperation of all six branches of NEIC. A typical NEIC study consists of the following six phases: planning, preliminary field reconnaissance, field work, laboratory work, evaluation and interpretation of data, and reports.

Althuugh the six branches cooperate in all phases of a study, not all will contribute proportionately in each of the six phases, but rather, will contribute when or where their expertise is needed. Fur example, technical services and field operations contribute substantially to the planning phase, while chemistry and biology conduct most of the laboratory work. Field work is coordinated by field operations with participation by chemistry, biology, and process control. Final reports are compiled by technical services with contributions from all of the branches.

\section{; Manning}

Background information is compiled prior to conducting an on-site investigation, survey, or study. The data are made available from a variety of sources including the requestor of the survey, regional and state offices, on-site records, permits, and historical information from various computerized national data bases. The permits show compliance schedules, effluent limitations, parameters, and monitoring requirements. The information is evaluated both to establish whether preliminary site reconnaissance is needed and to design a study plan that includes an adequate sampling program with a reasonable time frame for field investigations and laboratory work.

A study coordinator is usually selected from each branch to coordinate the activities of that branch. Preparations are then made to ensure the availability of resources including personnel, field and laboratory testing capabilities, and available equipment and supplies.

A briefing session is conducted to review all aspects of the survey prior to the actual field work. For example, chemistry reviews the nature and numbers of samples, the parameters to be determined in the field and in the Denver laboratory, the holding times of samples, any unusual tests to be performed, time schedules for sample acquisition, their shipment from the field, expected receipt in Denver, chain-of-custody procedures, and reporting of results.

Because of the widely differing conditions and objectives of each NEIC survey, it is important to 
understand that concentrated effort is required to prepare for and to perform most of the tasks within the specified time frame. In addition, each survey involves installing and dismantling different kinds of equipment $i_{n}$ the field, ordering new supplies, and often preparing for a completely new set of tests.

\section{Preliminary Reconnaissance}

A preliminary reconnaissance is usually conducted to validare the background information and data to be used in the study plan. It also allows the NEIC team to check the number and location of outfalls for sampling purposes, the flows involved, any operational problems, possible locations for mobile laboratories, and other information that will aid in developing the study plan.

\section{Field Work}

Field work is not the same for each branch. The chemistry and biology branches perform unique tests in suppori of the field operations branch, and many of the tests are conducted in mobile field laboratories. For example, when the chemistry branch field team arrives at the study site, they set up their laboratory, prepare reagents and glassware, run standards, and perform preliminary tests to be certain that the methods and inst $t_{4}$ uments are performing properly. When sampling begins, efficient operation must be maintained to ensure reliable sample identification and testing. More details of these procedures will be described in subsequent sertions of this study.

\section{Laboratory Work, Data, and Reports}

Most of the Denver laboratory work is conducted by the biology and chemistry branches. The work of the biology branch is compiled into reports that include both data summaries and text. Much of the work of the chemistry branch is compiled into data summaries that are forwarded to the field operations branch for inclusion in reports. Some of the chemistry results, for example, gas chromatography/mass spectrometry (GC/MS), must include text and spectra along with data to present a complete, informative analysis.

\section{Function of the Chemistry Branch In a Typical Survey}

The chemistry branch participates in all six phases of a typical survey. Its primary functions are to provide reliable parameter determinations as quickly as possible both in the field and in the laboratory.

The proportion of activities within the chemistry branch differs from those of the overall center because more time nust be spent on various complex organic analyses (e.g., chromatographic and $\mathrm{GC} / \mathrm{MS}$ methods) related to water and pesticide enforcement studies. Also, the Chemistry branch is not as actively involved in process evaluation and SIP inspections.

\section{Analyses Performed}

Gravimetric determinations of oil, grease, and various types of solids comprise a majority of field analyses. In recent surveys, a large number140/day-of lithium determinations have been required to calculate stream and effluent flows. These determinations are made in the Denver laboratory, but should be made in the field to provide timely data to the survey team.

Many parameters are determined in the Denver laboratory, mainly using instrumental techniques. Some of the more frequently used instruments are atomic absorption, optical emission, ultraviolet, visible, and $x$-ray fuorescence spectrometers, as well as Technicon AutoAnalyzer systems, gas and liquid chromatographic and GC/MS instruments, radioactive counting equipment, and carbon analyzers. Several manual multistep methods such as biological oxygen demand analyses are also used.

Surveys differ markedly in the type and number of parameters that are requested for determination. The requests may distribute the workload over the full range of analytical methods or only concertrate on a few methods (see Table 1).

It is important to note this diversity because the chemistry branch must maintain personnel, expertise, and equipment to respond to the wide variety of requests that occur throughout the year while also being able to respond to an intensive workload in a narrow area of expertise.

\section{Division of Responsibility}

The chemistry branch supervisor is responsible for properly conducting surveys, studies, case preparations, and other NEIC activities. For each specific study he assigns a person responsible for coordinating sampling and analyses for the study. The coordinator must keep the supervisor and key personnel apprised of any changes in the study plan especially with regard to the numbers and kinds of samples to be taken, and the time frame within 
Table 1. Parameters determined during four surveys in 1975.

\begin{tabular}{|c|c|c|c|c|}
\hline \multirow[b]{2}{*}{ Method of andysis } & \multicolumn{4}{|c|}{ Survey } \\
\hline & 1 & 2 & 3 & 4 \\
\hline Hiochemical oxygen demand (BOD) & - & $38^{\mathrm{a}}$ & - & - \\
\hline Chemical oxygen demand (COD) & - & 26 & - & - \\
\hline Electronic balan se (gravimetric) & $420^{3}$ & $213^{\mathrm{a}}$ & - & - \\
\hline Spectrophotometer & - & 8 & 82 & - \\
\hline Technicon AutoAnalyzer & 336 & 115 & 82 & - \\
\hline Total organic carbon analyzer (TOC) & - & 13 & - & - \\
\hline Atomic absorption spectrometer & - & 176 & 656 & 一 \\
\hline GC/MS & - & - & - & 192 \\
\hline Other & - & $21^{2}$ & - & - \\
\hline
\end{tabular}

${ }^{a}$ Field analysis.

which the results are needed. He must decida which samples to run in the field and which to run in the laboratory, according to the recommended maximum holding times for the samples and resources as well as time available to perform the work. It is his responsibility to ensure that the identification and integrity of the samples and data are maintained and documented according to the chain-ofcustody procedures.

\section{Information and Data Flow, Chain of Custody, Records and Reports}

The overall course of a study is formulated during the planning phase. The study plan shows the numbers and kinds of samples as well as locations from which th ey are to be taken. Samples are identified with a 1 ig showing the station number, location, date, tir te, sequence number, and parameters requested. Other remarks, such as preservative added, may als 3 be entered. A record of the chain-ofcustody of the sample starts at the time of sampling. The ch in-of-custody sheet, containing much the same it ormation found on the sample bottle tag, accomy inies the sample wiether it is sent to the mobile ield Jaboratory or to Lenver. When possession of the sample or group of samples is transferred from , le person to another, the record sheet must be sig...ed by both persons and the date and time of transfer recorded.
When the analysis is performed in the field, the raw data are recorded on bench cards along with instrument conditions, dilution factors, standards data, and calculations. Multiple parameter determinations in multiple samples are then summarized on analytical data sheets.

When samples are shipped from the field to the Denver laboratory, the information on the sample tags is checked against the custody sheets to verify consistency. The samples are then signed over to the laboratory custodian after noting the date and arrival time of the samples. Although a log-in record is kept, the chain-of-custody sheets, for all intents and purposes, act as log-in sheets. The custody sheets are also checked against the study plan to determine if the appropriate kinds and numbers of samples have been received.

Each analyst refers to a copy of the study plan to schedule his work. For example, if the analyst specializes in metals analysis by atomic absorption spectrophotometry, he refers to the plan to determine the samples that he will analyze, selects his samples, performs the analyses, calculates the results, and then makes them available to the study coordinator. The coordinator checks the calculations, standards, and quality contiol data, and enters the final summary of results on the analytical data report form. The results are subsequently checked by the chemistry branch quality control officer. He examines the data from replicate analyses 
and standard additions to determine whether precision and accuracy criteria have been met. Statistical data from normally consistent methods are also examined and Shewhart reference warning limits are set for data acceptability. If these limits are exceeded, steps are taken to identify and correct possible problems in the analytical method. The summary analytical data forms are then passed on to the chemistry branch supervisor, the data are checked, and it is determined whether reruns are necessary.

Chain-of-custody rules are always followed to ensure the integrity of samples and to document sample possession.

During the course of laboratory operations, records are maintained by the individual analysts, the study coordinator, the quality control officer, and the branch supervisor. Bench cards containing raw data, various identification entries, dilution factors, and parameter determination calculations are signec and dated by the analyst and forwarded to the quaiity control officer. The analyst will often retain strip charts and other raw data records. The analytical data report form with the final results for multiple parameters in multiple samples is retained by the chemistry branch supervisor. Copies may be retained by the study coordinator and quality control officer for a limited time to keep track of a study or make a statistical study of a group of samples. The analytical data report is sometimes the only formal data report generated by the chemistry branch. It is sent to the field operations branch which further processes the data to conyert the concentration units (e.g., mg/l) to loads in metric and/or English units (e,g., kg/day, lb/day). The latter units are calculated using effluent or stream flow data that are expressed in $\mathrm{m}^{3} /$ day. The field operations branch then incorporates the data into a report form suitable for inelusion in the formal NEIC report of the study or survey.

Because of a lack of time and manpower, chemistry data presently submitted to the field operations branch is unsuitable for their direct use and must be rewritten for the final report.

\section{APPROACHES TO AUTOMATION}

\section{Scope and Constraints}

Laboratory automation systems have already been designed and installed in three EPA water analysis laboratories: the Environmental Monitoring and Support Laboratory (EMSL), and the Municipal Environmental Research Laboratory (MERL), both in Cincinnati, and the Region V Laboratory (CRL5) in Chicago. They were designed for use with many of the same types of instruments usid by NEIC for water-sample analysis. The systems represent a large investment in hardware and software by EPA, and it is imperative in this study that we accord them primary consideration relative to the needs of NEIC.

We have described the overall mission of NEIC and the functions of the six branches. All branches could greatly benefit from an in-house computer system. The management at NEIC has compiled a list of areas for automation, including reduction of meteorological measuring system data, * reduction of airborne remote sensing of water and air pollution system data, ${ }^{\dagger}$ data management for microbiological parameters and bioassay samples, applied programs and systems for the biology, field operations, proce:is control, technical operations,

\footnotetext{
-Ref., solicitation number WA75E086.

${ }^{\dagger}$ Ref., solicitation number WA76E070.
}

and ait technology branches, and numerous management reports for the director of the office of planning and management relative to project status, property, and finances. It should be emphasized that we are not considering these needs in this study. We are only concerned with a computer system to handle the needs of chemistry and closely related operations. Nevertheless, it should be understood that the above constraints do not necessarily preclude future expansion to accommodate some of the other NEIC needs.

\section{Goals of the Chemistry Branch}

The chemistry branch has two main objectives: to respond quickly to analysis requests, and to perform the analyses with optimum reliability. These are continuing goals that bave been met in the past by acquiring new analytical instruments and improving existing methods and techniques. Further improvements appear possible through the use of computer automation in the laboratory. Automation objectives are;

- To link individual laboratory instruments to a system that will acquire and process data, perforin quality control tests, and store data for subsequent recall and compilation of a summary analysis report. 
- To determine quality control results while samples are being run.

- To perform quality control studies to establish the acceptability of data.

- To ensure the integrity and retention (backup) of the analysis data so that no data can be altered or lost.

- To track chain-af-custody of the samples.

- To reduce the number of data transcriptions and to perform calculations more rapidly.

- To reduce or eliminate possible errors in the above steps.

- To enter data off-line from low-use and nonautomated methods.

- To log in sample data, requested analyses, changes in the study plan, and other information pertinent to both the analyses and the eventual final report.

- To determine the status of samples and the parameters completed relative to the study plan.

- To list work schedules of samples or parameters to be run.

As described previously, many analyses are performed in mobile laboratories in the field. The most frequent requests include determinations of solids in water samples and lithium in flowing streams. In recent surveys as many as 140 lithium determinations per day have been done. These determinations require many data transcriptions, calculations, and the maintenance of record sheets. The NEIC eventually hopes to automate these latter steps so that data can be transmitted more quickly to the field operations team and ultimately to the Denver laboratory.

\section{Candidate Instruments for Automation}

Because many of the instruments used in the NEIC chemistry branch are already automated in other EPA laboratories, they are prime candidates for automation. Most of the software has been developed and the hardware interfacing designed, and thus, the only cost incurred by NEJC would be that of fabricating the interfaces. These inst ruments are:

- Perkin-Elmer AA spectrophotometer 403.

- Perkin-Elmer AA spectrophotometer 306.

- Technicon AutoA nalyzer II.

- Mettler electronic balance.

- Jarrell-Ash ICP emission spectrometer.*

\footnotetext{
- Direct interfacing of spectromcter data output to a Data General computer is being developed. The link to the Data General computer will provide additional data storage, data manipulation, and report formatting.
}

\section{Atomic Absorption Spectrophotometer}

The atomic absorption spectrophotometer is used to determine metals in water samples. It consists of a characteristic atomic line source (hollow cathode lamp) of the metal to be determined, a flame or furnace source for exciting metals in the sample, a monochromator to select light of the appropriate wavelength, and a photomultiplier tube to detect that light. Water samples are aspirated into the flame or injected into the furnace located between the holow cathode lamp and the monochromatordetector. Neutral atoms of the metal of interest absorh light from the hollow cathode, and the decrease in light energy (absorption) is detected and measured. The value can either be read on a digital display in absorbance units or directly in concentration, which is proportional to absorbance.

Perkin-Elmer spectrophotometer models 306 and 403 determine approximately 20 different elements in water samples. The workload has been erratic, ranging as high as 650 determinations for one survey to 10 or less for others. The demand for atomic absorption spectrophotometry to determine lithium in stream flows is expected to continue. Although lithium determinations are made in the Denver laboratory, they would be most effective if performed in the field.

\section{Technicon AutoAnalyzer}

The AutoAnalyzer performs continuous-flow multiple chemical analyses. The system aspirates samples in sequence, brings the samples and reagents togcther for reaction, and continuously moves the sequence of samples through predetermined a nalysis steps. The analyzer flows the colored solution through a colorimeter to measure light absorption. The concentration, which is proportional to absorbance, can be presented on a recorder or digital tape. Three dual-channel Technicon AutoAnalyzer II systems are used to determine analytes such as phenol, Kjeldahl nitrogen, $\mathrm{NH}_{3}$, $\mathrm{NO}_{3}-\mathrm{NO}_{2}$ forms of nitrogen, various forms of phosphorus, and others. The workload is again erratic, with a high of 680 determinations for single survey.

\section{Mettler Electronic Balance}

The Mettler electronic balance system is composed of the model HE10 balance, model BE10 control, and the model BA28 electronic digital readout. The system is most often used to determine the weight of suspended solids, oil, and grease in water, as well as particulate matter on filter papers. The electronic balance determines more parameters than any other instrument. However, to date most of 
these determinations have been made in the field with as many as 750 performed in a sirgle survey. As a result of a recent change in methodology, all suspended solids weighings will eventually be performed in the Denver laboratory, which should transfer a large fraction (approximately 1100 ) of the fjeld weighings to Denver.

In addition, the establishment of an air pollution program at NEIC is greatly affecting the electronic balance workload. A study presently in progress will require about 1800 air particulate analyses over a six-month period. These will all be performed in the Denver laboratories.

\section{Optical Emission Spectrometer}

Trace metals in water samples and residues are determined on a Jarrell-Ash optical spectrometer equipped with an incuctively coupled argon-plasma excitation source. The sample is nebulized to form an aerosol and is injected into high-temperature argon gas that is heated in a radio-frequency field. Radiation from the plasma (characteristic of the excited argon and impurity atoms) is dispersed in the grating spectrometer. It is then focused on separate slit-photomultiplier tube assemblies (channels) precisely arranged along the focal plane of the spectrometer to detect each element of interest. The signals deteeted in each channel are processed by a minicomputer and typed out directly in concentration units for each element. The minicomputer is an integral part of the spectrometer.

The optical emission spectrometer was recently acquired by the chemistry branch. It is expected to be used to determine many of the metals that are currently ascertained by atomic absorption spectrophotometry because it is precise, accurate (at least equivalent to atomic absorption for many elements), and can process more samples.

\section{Other Instruments}

A variety of different instruments is used in the laboratory including $\alpha$ and $\gamma$ counting equipment, optical and $x$-ray fluorescence spectrometers, and colorimeters. However, they do not have a workload high enough to warrant the development of hardware and software for automation. For example, during 1975 , the optical fluorescence spectrometer was used for one survey to determine uranium in 134 samples.

Chromatographic and GC/MS instruments are integrally automated or semiautomated. Further automation via a link to a laboratory automation system may not be justified at this time because of the sample workload. For example, during 1975, a total of 374 trace organic analyses were performed by GC/MS. Note that these were complex. timeconsuming analyses that could only have been handled by the minicomputer system integral to the instrument, but that further automation was not needed to handle the workload.

\section{The Study Plan, Job Scheduling, Coordination, and Sample Management} Activities to be Automated

\section{Study Plan}

A study plan includes, among other things, tables that contain lists of samples to be determined. The tables essentially describe the database containing all data from chemical tests conducted both in the field and in the Denver laboratory. They constitute the schedules through which the chemistry branch can plan its work, determine the status of a survey, fulfill changes therein, and generate reports.

The present system has several shortcomings. For example, copies of the study plan must be distributed among survey participants. Copies can be mislaid or lost and new copies must be acquired. In addition, the study plan is often changed after the study or survey has begun. These chainges are often initiated in the fjeld and must be transmitted to all participants. There are problems in ensuring that the changes are documented and that the correct information is included.

Throughout the survey, information and data are often transcribed both in the field and in the laboratory (Fig. 1). Numerous records are maintained by all participants. and these inust be compiled into a unified report. Thus, the present system requires much coordination and diligert rechecking to ensure that the information and data flow are correct and that they proceed smoothly within the time constraints set by the study plan. It is also obvious that these processes would be more efficient and reliable if data acquisition, transcriptions, and record keeping were minimized. The sollowing is a description of minimal functions that may be automated:

- The sampling table can be made available in one or more computer files so it can be arcessed to provide local laboratory work schedules and to determine the status of the study plan relative to parameters in samples conpleted. Provide hard copy.

- Update computer files with analysis results and changes in the study plan relatuve to the sampling table.

- Provide the means to amend the samplin. table with upproved resuits from rerun samples. 


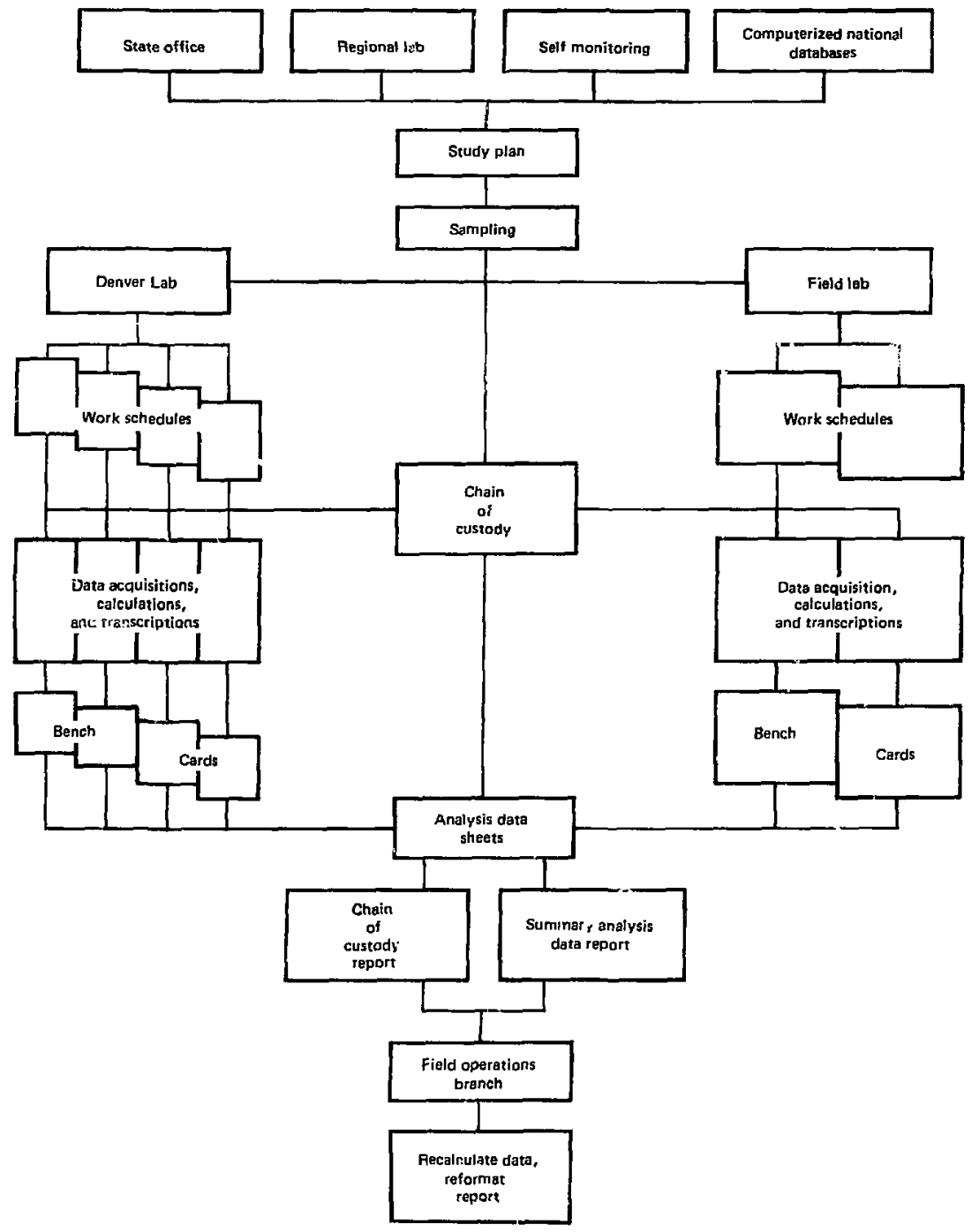

Fig. 1. Survey information and data flow. 
- Provide the mearis to review all analysis results in the sampling table for the purpose of approving the final analysis report.

- Make available a lccal analysis file listing samples to be run according to in common parameter test. Provide hard copy.

Make provisions for updating the local analysis file with results as they are generated.
- Provide the means to review iocally compjeted analyses and quality controls. Provide hard copy. (Note: The hard copy can be dated and signed by the analyst and quality control officer and rctained as backup evidence.)

- Provide a file for recording chain-of-custody of samples. Provide hard copy.

- Provide a means for entering field data into the sampling table computer file.

\section{PROPOSED SYSTEMS FOR FULFILLING THE REQUIREMENTS OF THE CHEMISTRY BRANCH LABORATORY}

We have proposed five optional automation systems. System configurations are shown in Fig. 2, and the one-time system costs are listed in Table 2. The costs pertain to the computer and peripherals, hardware interfaces, software, site preparation, spare parts, test equipment, and system installation.
Also included for options 3, 4, and 5 are the costs for communications hardware and software that allow the laboratory automation system to communicate with a management system for sample file contral (SFC) functions. We assume that the pronosed management computer system (DEC

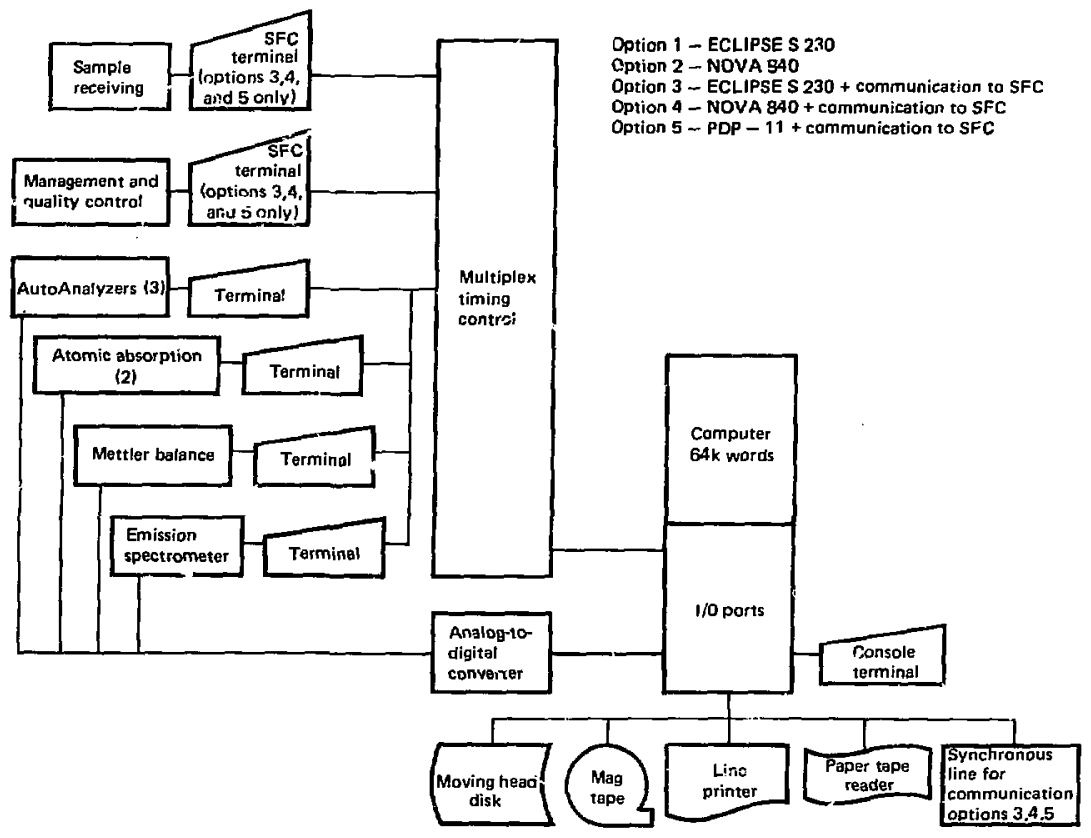

Fig. 2. Five proposed options for automation of NEIC chemistry branch laboratory. 
Table 2. Costs of proposed optional computer automation systems.

\begin{tabular}{|c|c|c|c|c|c|}
\hline Component & Option 1 & Option 2 & Option 3 & Option 4 & Option 5 \\
\hline Computer and peripherals & $\$ 83,046$ & $\$ 16,376$ & $\$ 119,586$ & $\$ \$ 2,916$ & $\$ 172,175$ \\
\hline Terminals & 10,000 & 10,000 & 19,800 & 19,800 & 19,800 \\
\hline Site preparation & 20,000 & 20,000 & 20,000 & 20,000 & 20,000 \\
\hline Spare parts and test equipment & 10,000 & 10,000 & 10,000 & 10,000 & 10,000 \\
\hline System installation & 33,500 & 33,500 & 33,500 & 33,500 & 33,500 \\
\hline Instrument interfaces & 16,700 & 16,700 & 16,700 & 16,700 & 21,200 \\
\hline Software & No cost & No cost & 20,000 & 20,000 & 141,000 \\
\hline Total one-time costs & $\$ 173,246$ & $\$ 106,576$ & $\$ 239,586$ & $\$ 172,916$ & $\$ 417,674$ \\
\hline
\end{tabular}

PDP-11/70) will have been justified for management needs and will not be a cost incurred by the chemistry branch of NEIC. More details of the costs are presented in Appendix B.

The first option is based on the EPA standard laboratory automation design currently installed in water analysis laboratories in Cincinnati and Chicago. The system incorporates a Data General ECLIPSE S 230 computer that uses the MRDOS operating system and BASIC high-level language programming capability. The EPA system also includes laboratory instrument interface designs and BASIC language programs with assembly language routines to operate the laboratory instrument automation. Appendix A describes the computer hardware, interfaces, and software that comprise the system. Although this system is embodied in the current EPA design, the computer hardware differs from the currently installed systems to the extent that more recent designs of the central processor and peripheral devices are proposed. This new generation equipment is compatible with the analytical instrument hardware interfaces and applications programs already in use.

The second option is also based on the standard EPA design and proposes a NOVA 840 computer that is currently available from the computer services and systems division in Cincinnati, at no cost to NEIC-Denver.

The third option is an outgrowth of the EPA decjsion to adopt the Digital Equipment Corporation PDP-11 system for decentralized processing. The option proposes the standard EPA laboratory automation system (same as option 1), with added hardware and software to communicate with a host PDP-11 for sample file control (SFC) functions.

Option 4 is the same as option 3 but would use a NOVA 840 computer for laboratory automation.

Option 5 also considers the EPA commitment to PDP-11 conputer systems and proposes that laboratory automation be performed on a PDP-11. This option would include hardware and software to communicate with a host PDP-11 for SFC functions.

\section{COST-BENEFIT ANALYSIS}

\section{Preliminary Remarks}

We must now demonstrate the extent to which the chemistry branch can justifiably incur the costs i. light of expected benefits from the proposed optional systems. Thus, we must place a dollar value on benefits vs dollar costs.

\section{Basis for the Analysis}

To perform the analysis we must estimate the workload expected in the next two to three years, at which time an automation system would be implemented. We must also compare the effort and operating costs required to meet the load with and without the automation.

We will use 1975 figures to project the future workload. As stated earlier, the work over the course of each year is not uniform, but fluctuates drastically from one survey to another. The survey workload for 1975 is illustrated in Fig. 3. A total of 8344 determinations were made in 31 studies and surveys. Of the total determinations, $37 \%$ were performed in the field, and $83 \%$ of the field determinations were gravimetric analyses 


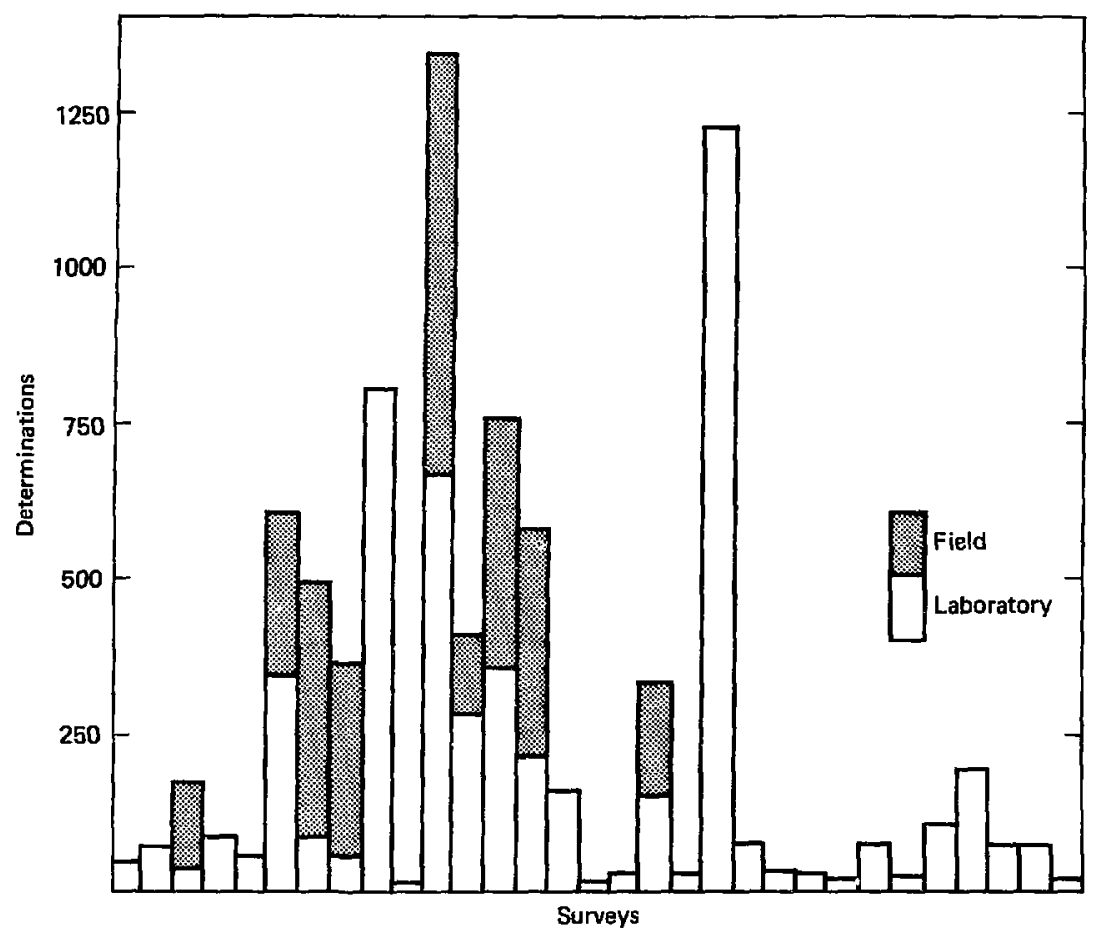

Fig, 3. Summrry of surveys and determinations for 1975.

(weighings) of various solids, oils, and greases. Table 3 gives a breakdown of the analysis methods and the percent of total determinations performed by each method. It should be emphasized that the percentages in Table 3 do not reflect the effort required to perform the determinations. For example, it is estimated that $35 \%$ of laboratory effort is devoted to organic analysis by chromatography, the combined technique of GC/MS, and other organic analysis methods. These methods are much more complex than, for example, atomic absorption spectronietry and Technicon AutoAnalysis which are used for the determination of more simple inorganic analytes.

In addition to the 8344 determinations already mentioned, 1100 determinations related to methods development and verification were conducted.
Thus, the total workload for 1975 amounted to 9444 determinations. Within the next two years this workload is expected to double. This has already been made evident by modifications to current methodology and the introduction of new programs previously described. Therefore, the workload is expected to approach or surpass 18,000 determinations per year and will be handled by approximately the same level of staffing.

During 1975, the chemistry branch employed an average of 16 people in the laboratory and the field. including the chemistry branch supervisor, a secretary, and the staff of chemists and technicians. The effort of the branch personnel can be broken down into three categories: administrative and supervisory tasks (to coordinate, collate, and summarize analysis data), laboratory and field 
Table 3. Analysis methods and percent of determinations performed.

\begin{tabular}{lc}
\hline \multicolumn{1}{c}{ Method } & $\begin{array}{c}\text { Total } \\
\text { determination:, }\end{array}$ \\
\hline Technicon AutoAnalysis & 20 \\
Atomic absorption spectrometry & 20 \\
Gravimetric analysis & 34 \\
and counting & 4 \\
Fluprometric analysis & 2 \\
Colorimetric analysis & 1.5 \\
Organic analysis (GC, GC/MS, etc.) & 7.5 \\
BOD analysis & 5.5 \\
Total organic carbon analysis & 0.2 \\
Wet chemistry and miscellaneous tests & 5.3 \\
\hline
\end{tabular}

work, and quality control. Administration and supervision includes $100 \%$ of the time of the branch supurvisor and secretary, $30 \%$ of the time of a project coordinator, and $5 \%$ of the time of each of 10 staff members, for a total of 2.8 full time employees (FTE), For the laboratory and field effort, an average of 1.5 FTE are assigned to field work, 5 FTE to organic analysis, and 6.5 FTE to the remaining analytical disciplines and laboratory functions. The quality control effort includes the specific tasks related to checking the quality control of the laboratory. These tasks consume $30 \%$ of the time of a staff chemist (0.3 FTE) who is the designated quality control officer. Note that quality control standards are used to check all analytical methods. The time devoted to preparing and running these standards is not included in the quality control officer's tasks but rather in the laboratory effort associated with each analysis. The quality control officer ensures that quality control procedures are followed and that all criteria are met.

Closely related management tasks are conjucled by the fieId operations branch. These were described earlier in the section entitled lnformation and Data Flow, Chain of Custody, Records and Reports. These operations, including recalculating data and reformatting reports, consume $100 \%$ of the time of two people in the field operations branch.

Workload figures from 1974 and 1975 indicate that the workload for the total organic carbon analyzer is low and therefore it would not be beneficial to automate the system at this time. We are also not considering the ICP emission spectrometer system in this study because the workload has not been established. The emission spectrometer contains its own computer system for data acquisition, reduction, and individual sample report generation. Any additional automation would consist of linking the spectrometer output to the laboratory automation computer to store and manipulate results for multiple samples. This should be considered a SFC function.

\section{Comparison of Costs and Benefits}

To assess the benefits that will accrue to NEIC as a result of automation, we compare the effort expended by manual methods to the estimated expended effort by computer automation.

Increased efficiency as a result of automatior: can be expressed as FTE effort made available for other tasks such as performing more analyses or conducting more surveys. Table 4 summarizes the benefits expressed in increased efficiency. Details of the assessment are given in Appendix C. On-line instrument automation and on-line quality control will make available 1.20 FTE, while sample management automation will free another 2.83 FTE. The laboratory's expected average annual cash outlay per emplicyee will be approximately $\$ 40,000$ * The savings attributable to laboratory automation and quality control of $1.20 \mathrm{FTC}$ are equivale: $t$ to $\$ 48,000$ per year; the savings of 2.83 FTE in management effort are equivalent to $\$ 113,200$ per year. Thus, the total annual benefit accured to NEIC is $\$ 161,200$.

Table 2 lists the basic costs for each of the five proposed systems. In addition to these costs it is essential to include annual maintenance and operating costs. These costs, which are over and above

- We assume a median salary level of $\$ 18,000$ per year multiplied by factors of 1.3 and 1.67 to account for benefits and overhead, respectively.

Table 4. Summary of benefits.

Candidate area for automation

Efficiency, FTE

\begin{tabular}{lc} 
Instruments & 0.95 \\
Quality control & $\underline{0.25}$ \\
Subtotal & $\frac{1.20}{}$ \\
Sample management & \\
$\quad$ Chemistry branch & 1.33 \\
Field operations branch & $\underline{1.50}$ \\
Subtotal & $\mathbf{2 . 8 3}$ \\
Total & - \\
\hline
\end{tabular}


any current annual costs, are $\$ 30,000$ for options I and $2, \$ 58,400$ for options 3 and 4 , and $\$ 65,700$ for option 5 . The latter costs are higher because of maintenance and operation of communications with SFC. A description and breakdown of these costs for the five options are given in Appendix $\mathbf{D}$.

\section{Costs and Benefits Relative to Payout Time and System Life}

Two criteria that indicate feasibility of automation are the accumlated benefits at five years of system service, and the payout time of the system. In this study we calculate the criteria for each of the five options. However, note that options 1 and 2 propose laboratory automation systems only, and do not provide communications with a laboratory management (SFC) computer. Therefore, only benefits derived from on-line instrument automation and quality control (1.20 FTE, equivalent to $\$ 48,000$ per year) can be considered for the first two options. Also note that the annual benefits for the five options must be balanced against the added operating costs incurred as a consequence of the automation options.

The accumulated balance at five years service, ${ }^{*}$ is calculaied using the following formula: ${ }^{2}$

$$
B=\frac{b}{i}\left[1-\frac{1}{(1+i)^{n}}\right]-C \text {, }
$$

where

$\mathrm{B}=$ balance after $\mathrm{n}$ years,

$b=$ net benefit per year,

$j=$ interest rate $(10 \%$ per annum),

$\mathrm{n}=$ number of years (5),

$c=$ one-time investment cost of the system.

* System service life is considered to be live years. Refer to Bureau of the Budget Circular A54.
Payout time is that time when initial costs will have been balanced by the accumulated benefits. Thus $B$ in the above equation may be set to zero and the payout time, $n$, can be solved as follows:

$$
\pi=-\log \left(1-\frac{i c}{b}\right) / \log (1+i) .
$$

Table 5 gives a summary of the costs, benefits, and calculated feasibility criteria for the five optional automation systems.

\section{Cost-Benefit Study Summary}

From a cost-benefit point of view, options 3 and 4 of the proposed automation are economically justifiable. The NEIC will sccrue net equivalents of $\$ 150,106$ and $\$ 216,777$ in increased effort efficiency over an expected system service life of five years. Also, the original investment costs for option 3 and 4 will have been paid up in 2.8 and 1.9 years, respectively.

Other benefits of automation will directiy influence the mission of NEIC to respond quickly to emergencies. On-line automation in the laboratory as well as a link with a sample management system will allow the Iaboratory to perform a study or survey at least twice as fast. Thus, the laboratory can respond more favorably to scvere peak load situations such as those in 1975 (see Fig. 3).

The proposed automation will help ensure improved quality. The present NEIC workload of samples includes approximately $15 \%$ quaity controls such as repeat standards, duplicate unknowns, and spiked unknowns. The goals of EPA are to increase quality control samples 20 to $40 \%$. Automation will provide NEIC with the means to handle these more intensive requirements.

Table 5. Summary of costs, benefits and calculated feasibility criteria.

\begin{tabular}{lrrrrr}
\hline \multicolumn{1}{c}{ Item } & Opricn 1 & Option 2 & Option 3 & \multicolumn{1}{c}{ Option 4 } & Option 5 \\
\hline One-time system costs & $\$ 173,246$ & $\$ 106,576$ & $\$ 239,586$ & $\$ 172,916$ & $\$ 417,674$ \\
Gross annual benefit & 48,000 & 48,000 & 161,200 & 161,200 & 161,200 \\
Added annual operating costs & 30,000 & 30,000 & $\$ 8,400$ & 58,400 & 65,700 \\
New annual benefit & 18,000 & 18,000 & 102,800 & 102,800 & 95,500 \\
Accumulated balance after 5 years & $-\$ 105,000$ & $-\$ 38,340$ & $\$ 150,106$ & $\$ 216,7 m$ & $-\$ 55,654$ \\
Payout time, yr & $>10$ & 9,4 & 2.8 & 1.9 & 6 \\
\hline
\end{tabular}




\section{OTHER RECOMMENDATIONS}

We previously stated that $37 \%$ of the chemistry branch determinations were performed in the field and that $83 \%$ of these were gravimetric determinations using an electronic balance. It seems worthwhile to consider automating (or at least the feasibility of automating) this effort using a portable computer system or a remote entry terminal linked to the laboratory computer system in Denvur. In addition, multiple lithium determinations for stream-flow measurements could benefit from automation. If lithium determinations are done in the field, the above recommendations should be strongly considered.

\section{REFERENCES}

1. Development of Laboratory Computer Automation Systems, Interagency Agreement, between Energy Research and Development Administration and Environmental Protection Agency, Rept. FPA-IAG-D60321 (1976).

2. F. J. Stermole, Economic Evalnation and Investment Decision Methods (Investment Evaluations Corporation, Golden, Colorado, 1974). 


\title{
APPENDIX A \\ PROPOSED OPTIONAL AUTOMATION SYSTEMS
}

\author{
Option 1: Standard EPA Laboratory Automation System, \\ ECLIPSE S230 Computer
}

The standard EPA laboratory automation system proposed as option 1 incorporates the general-purpose ECLIPSE S230 Data General computer and peripherals. The system also includes laboratory instrument interfaces and software designed and developed for the Data General NOVA 840 computer with the MRDOS operating system. Although developed for NOVA 840 , the interfaces and software are largely compatible with the ECLIPSE S230 system that also uses MRDOS.

\section{Computer and Peripherals}

Computer. The proposed Data General ECLIPSE S230 general-purpose computer has several features thit recommend it as a central processor for the NOVA 840 presently used in the Cincinnati and Chicago systems. It will perform at about twice the speed of the NOVA 840 , and like the NOVA 840 , will handle a range of software including, BASIC, FORTRAN IV, FORTRAN V, and ALGOL. In addition, as with the NOVA 840 , it can communicate with other vendor and Data General computers by means of HASP and 2780 emulators. The ECLIPSE S230, therefore, qualifies as a general-purpose computer compatible with the standard EPA software and interface bardware while also providing capabilities for future growth. We recommend 64K words of core memory.

Disk Storage. The proposed Data General model 6060 moving head disk has several features that recommend it over disk configurations used in previously installed EPA systems. It has storage capacity of $96 \mathrm{M}$ bytes, tranfers data at three times the rate of previous configurations, and is expected to be more reliable. While the storage capacity of the disk is far more than required to implement laboratory automation, it is recommended because smaller capacity units are not fast enough, and because combined fixed head and moving head units are nearly equivalent in cost.

Magnetic Tape. The magnetic tape system is used both for permanent storage of software programs and as a backup storage medium (i.e., backup relative to core memory and disk) for storing data and information accumulated over extended periods of time. The proposed magnetic tape unit drives the tape at 75 in. per second. We recommend this faster drive system, especially if data backup opera:ions are to take place on a daily or more frequent basis.

Line Printer. The line printer currently used produces hard-copy listings of programs, preliminary and final data reports, and multiposition sampler patterns. A fast unit is desirable in a multiuser automation system; thus, we propose a 300-line-per-minute unit for the NEIC system.

Peper Tape Reader. A paper tape reader is a recommended component of the standard EPA system. It is used to start the system and to diagnose hardware problems when disk or magnetic tape are not available.

Artalog-to-Digital Converter. We propose a multichannel analog-to-digital converter with full-scale resolution of one part in 16,384 . The converter is essential for digitizing the various analog signals from laboratory instruments interfaced to the computer system. The number of channels required equals the number of analog signals to be processed. We initially anticipate a total of nine channels; therefore, a 16-channel converter is recommended (a minimum of eight channel modules are provided). Sixteen channels provide an adequate complement of channels for spares and future expansion.

Terminals. Keyboard terminals enter and receive information. They are used at the computer, at the inierfaced laboratory instruments, and at other potential locations such as sample receiving and management offices. We are not recommending a specific type of terminal because system design is not complete. However, two general types are used in the standard EPA system. They are hard-copy teletype devices such as the Texas Instruments Silent 700 and the cathode ray tube (CRT) display devices. The latter may be obtained with the "roll back" feature that allows for rolling back lines of information or data that have disappeared from the screen because of limited line-display capacity. Special terminals equipped with keyboard, CRT display, hardcopy unit, and telecommunications accessories are recommended for those options that include communication with a SFC. 


\section{Laboratory Instrument Interfaces}

Laboratory instrument interfaces are electronic devices that link the analytical instruments to the computer. In the standard EPA system, interfacing bas been installed at the instrument signal output. The instruments to be automated can use the existing interface designs. Table A-1 lists the currently available interface designs and their applications.

\section{Software}

In the course of developing automation systems for EPA water quality laboratories, extensive software has been developed for use in a variety of laboratory instrument applications. The software includes both assembly language coding and high-level BASIC language programming. Table A-2 summarizes the programs developed to date that are considered part of the EPA standard system.

\section{Software Functions}

Software functions include:

1. Interactive input routine for setting up a schedule of samples, standards, and controls to be run on a sample changer.

2. Method and instrument operation prompts.

3. Sample changer control and monitor.

4. Sample changer monitor or.!y.

5. Data Acquisition.

6. Data reduction, standards, samples, and quality controls.

7. On-line results displayed or typed.

8. Report generation (exclusive for each instrument).

\section{Examples of Data Reduction Processes}

Data reduction processes include the following:

- Creation of standard curves using first-, sexond- and third-degree polynomial fits.

- Calculation of unknown concentrations by interpolation between the two nearest standards.

- Calculations of spike recoveries, checking standards compliances and differences between duplicates.

- Calculation of statistical error bands using Shewhart and Cusum Methods.

Table A-1. Currently available interface designs.

\begin{tabular}{|c|c|}
\hline Interface & Application \\
\hline General computer interface & Timing and control signals \\
\hline Technicon AutoAnglyzer I & Data signal acquisition \\
\hline Technicon AutoAnslyzer It & Data signal acquisition \\
\hline Perkin-Elmer AA spectrophotometer & Data signal acquisition \\
\hline Varian Techtron AA spectrophotometer & Data signal acquisition \\
\hline Instrumentation Lab AA spectrophotometer & Data signal acqujsition \\
\hline Sample wheel for AA spectrophotometer & Random and sequential sampler control \\
\hline Total organic carbon analyzer & Data signal acquisition \\
\hline $\begin{array}{l}\text { Jarrell ash emission spectrometer sequental readout } \\
\text { Uitravolet-Vlsible spectrophotometer }\end{array}$ & $\begin{array}{l}\text { Data signal acquisition and monitor chennel position } \\
\text { Data signal acquisition }\end{array}$ \\
\hline Graphite furnace for atomic ibsorption & $\begin{array}{l}\text { Detection of fumace cycles for control of signal } \\
\text { acquisition }\end{array}$ \\
\hline Mettler electronic balance & Date slgnal acquisition \\
\hline
\end{tabular}


Table A-2. Standard EPA laboratory automation system. Summary of applications programs for laboratory instruments.

Instrument

Technicon AutoAnalyzer

AutoAnalyzer I

AutoAnalyzer it

Atomic Absorption Spectrophotometer

Perkin-Elmer model 303

Perkin-Elmex model 306

Perkin-Eimer model 503

Varian techtron AAS

Instrumentation laboratory 453

Carbon andyzer

Beckman TOC, 915

Electronic balance

Mettier, HE20

Emission spectrometer

Jarrell Ash, Mark IV, spark excitation

Spectrophotometer

Perkin-EImer (Coleman) 124
Functions?

$12-45678$

$12-45678$

$123-5678$

$123-5678$

$123-5678$

$123-5678$

$123-5678$

$-2--5678$

$-2--5678$

$-2--5678$

$-2--5678$

${ }^{2}$ See the lists of functions ensumerated in the section entitled Software functions.

\section{Option 2: Standard EPA Laborator; Automation System, NOVA 840 Computer}

We are proposing the second option to NEIC because of recent notification of the availability of a NOVA 840 computer from the Computer Services and Systems Division (CSSD) in Cincinnati. It is our understanding that this computer and the associated peripinerals can be obtained at no cost to NEIC. Option 2 constitutes the original version of the standard EPA laboratory automation system. It incorporates the same hardware interfaces and software as described in Option 1.

The CSSD NOVA 840 computer includes 40,960 words of core memory, multiply/divide, floating point processor, memory management and protection unit, and real-time clock. Following are the peripherals available with the system:

- NOVA disk, fixed head disk drive, 524,288 16 bit words.

- Centronix, Model I04A, line printer.

- Paper tape reader, $400 \mathrm{cps}$.

- Castridg; disk drive with single removable disk.

- Magnetic tape unit, 800 or 556 BPI switchable transport.

- Synchronous line adaptor.

- Expansion chassis.

\section{Option 3: Standard EPA Laboratory Automation System, ECLIPSE S230 Computer With Communications to a PDP-11 Computer for Sample File Control}

Option 3 is an outgrowth of the EPA decision to adopt the Digital Equipment Corporation PDP.11 system for decentralized processing. It is composed of the standard EPA laboratory automation system with 
the ECLIPSE S230 computer described in option 1. In addition, it includes hardware and software to communicate with the PDP-11 computer for SFC functions.

Hardware is required on both ends of the communications link. The laboratory will require a synchronous line adaptor and the SFC computer will need an additional disk drive and a full/half duplex synchronous interface. Two console terminals equipped with a keyboard, cathode ray tube display, and printer will be needed in the laboratory to facilitate communications with the PDP-11.

The ECLIPSE S230 computer contains the Data General version of the Houston Automatic Spooling Process (HASP) emulator for communications with the PDP-11. However, appropriate software that uses HAS $^{\text {P }}$ will have to be developed to send data to the PDP-11 via the synchronous line adaptor.

\section{Option 4: Standard EPA Laboratory Automation System, NOVA 840 Computer With Communications to a PDP-11 Computer for Sample File Control}

Option 4 is the same as option 3, but incorporates a NOVA 840 computer for laboratory automation. Refer to option 3 for communications details and to option 2 concerning the NOVA 840 and peripherals.

\section{Option 5: Laboratory Automation Using Digital Equipment Corporation PDP-11 With Communications to a PDP-11 Computer for Sample File Control}

Option 5 is also based on the EPA commitment to PDP-11 computer systems. The standard EPA laboratory system would be modified both in hardware and software to run on a PDP-11 system. Modifications include redesign of the general computer interface to the instrument automation system and extensive rewriting and debugging of the automation software. More details are presented in Appendix B. The option also includes communications to the PDP-11 for SFC functions. 


\section{APPENDIX B \\ ONE-TIME COSTS FOR THE FIVE PROPOSED COMPUTER AUTOMATION SYSTEMS}

\section{Computer and Peripherals}

The costs for the computer and peripherals for the five proposed optional automation systems are listed in Table B-1.

\section{Terminals}

Five terminals are recommendcd for options 1 and 2, including one terminal at the computer console (that can be switched between foreground and background) and four at each of four instrument installations. The estimated costs of these terminals is $\$ 2,000$ per terminal for a total cost of $\$ 10,000$.

For options 3 through 5 , seven terminals are recommended including two special terminals for communications with the SFC computer in addition to the five already described. The two SFC terminals will be equipped with keyboard. CRT display, hardcopy unit, and telecommunications accessories. The estimated costs of these terminals is $\$ 10,000$ for the console and four instrument terminals, and $\$ 4,900$ each ior the two SFC terminals. Thus, the total cost is approximately $\$ 19,800$.

Table B-1. Costs of computer hardware and peripherals.

\begin{tabular}{|c|c|c|c|c|c|}
\hline Component & Option 1 & Option 2 & Option 3 & Option 4 & Option 5 \\
\hline $\begin{array}{l}\text { Computer with } 64 \mathrm{~K} \text { wotds core memory, floaring point } \\
\text { processor, memory map, and real-time clock }\end{array}$ & $\$ 29,930$ & $37,872^{\mathrm{a}}$ & $\$ 29,930$ & $\$ 7,872^{2}$ & $\$ 51,660$ \\
\hline Moving head disk, $96 \mathrm{MB}$ & 21,930 & $-b$ & 21,930 & $-\mathbf{b}$ & 36,750 \\
\hline Magnetic tape & 7,380 & $-c$ & 7,380 & $-c$ & 26,500 \\
\hline Line printer & 9,812 & $-d$ & 9,812 & $-d$ & 11,800 \\
\hline Paper tape reader & 1,640 & $-e$ & 1,640 & -e & 5,060 \\
\hline System cabinet & 2,850 & 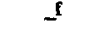 & 2,850 & $-\mathbf{f}$ & - \\
\hline Analog-to-digital converter, 16 channels & 4,904 & 4,904 & 4,994 & 4,904 & 4,904 \\
\hline Multiplexer asynchronous line & 3,600 & 3,600 & 3,600 & 3,600 & 3,600 \\
\hline Computer system software & 1,000 & $\boldsymbol{g}$ & 1,000 & $\mathcal{B}$ & 3,660 \\
\hline $\begin{array}{l}\text { Communications hardware synchronous line } \\
\text { adaptor (Laboratory) }\end{array}$ & - & - & 1,100 & $-h$ & 1,300 \\
\hline $\begin{array}{l}\text { Communications hurdware fullthelf duplex } \\
\text { synchronous interface (PDP-11) }\end{array}$ & - & - & 3,100 & 3,100 & 3,100 \\
\hline Additionel dlsk drive, 88 Mbyte (PDP-11) & - & $=$ & 32,340 & $\underline{32,340}$ & 32,340 \\
\hline Totu & $\$ 83,046$ & $\$ 16,376$ & $\$ 119,586$ & $\$ 52,916$ & $\$ 172,174$ \\
\hline
\end{tabular}

\footnotetext{
$24 K$ words of memory must be added to the NOVA 840 to bring it up to $64 K$ words core memory.

Include : 1.247-million-word disk drive with remowable diak cartridge.

G includer mantetic tape unit with 800 or S56 BPI switchable transport.

Indudes a Centronics Model 104A printer.

Includea a Data General 400 cps paper tape reader.

Includes a system cabinet.

Sincludes the syitem coftwars.

hIncludes a synchronous Itine adaptor.
} 


\section{Site I':eparation}

The computer must be located in a room about $1.50 \mathrm{ft}^{2}$ equipped with the necessary electrical and service utilities as well as air conditioning. Cables that link laboratory instruments with the computer must also be inttalled. W': estimate the total cost to be about $\$ 20,000$.

\section{Spare Paris and Test Equipment}

A mirimium complement of spare parts and test equipment are necessary to maintain the system. Spare parts should inciade control logic cards, power supplies, operational amplifiers, relays, and connectors at a cost of about $\$ 3,000$. The major test equipment item, an oscilloscope, will cost approximately $\$ 7,000$ for a total co:c of ahout $\$ 10,600$.

\section{System Installation}

Installation costs include shipping and installing the system in Denver, hardware and software checkout, operational testing of the complete system, and personnel training. The estimated total is about $\$ 33,500$.

\section{Instrument Interfaces}

Options 1 through 4 can use the existing interface designs from previous EPA int:allations. However, for option 5 it will be secessary to redesign the general computer interface (digital bay, etc.). We anticipate that the laboratory instrument interface designs for the existing system will apply to the PDP-11 system for option 5. Fabrication costs will be equal for all 5 options. Table B-2 gives interface design and fabrication costs.

\section{Soltware}

As with the instrument interfaces, options 1 through 4 can use existing laboratory instrument applications programs developed for currently installed EPA automation systems. Option 5 will require extensive modifications and debugging to adapt the automation software to a PDP-11 system.

We estimate that rewriting the assembly language code for the operating system and instrument programs (assembly language calls) will reyuire about $50 \%$ of the effort to develop the coding initially; rewriting the BASIC language applications programs will requirs about $35 \%$ of that effort. Table B-3 gives a breakdown of the software rewrite costs.

Table B-2. Summary of interface design and fabrication costs.

\begin{tabular}{|c|c|c|}
\hline Type of interface & Options $1-4$ & Option 5 \\
\hline General interface desifgr & - & $\$ 4,500$ \\
\hline General interface fabrication & $\$ 7,300$ & 7,300 \\
\hline AutoAnwyzer II fabrication & 6,200 & 6,200 \\
\hline $\begin{array}{l}\text { Atomic abrorption PE } 306 \\
\text { fabicntion }\end{array}$ & 1,300 & 1,300 \\
\hline $\begin{array}{l}\text { Atomk abmorption PE } 403 \\
\text { fabdcation }\end{array}$ & 1,300 & 1,300 \\
\hline Mettler balunce fibrication & 600 & 600 \\
\hline Totd & $\$ 16,700$ & $\$ 21,200$ \\
\hline
\end{tabular}

Table B-3. Cost of rewriting EPA software to operate on a digital equipment PDP-11 system.

\begin{tabular}{|c|c|c|}
\hline Rewrite tusk & $\begin{array}{c}\text { Assembly } \\
\text { language } \\
\text { code }\end{array}$ & $\begin{array}{l}\text { Batc } \\
\text { bngugpo } \\
\text { code }\end{array}$ \\
\hline Computer syatem programs & $\$ 41,000$ & - \\
\hline Technicon AutoAnalyzer program & 12,000 & $\$ 30,000$ \\
\hline Atomic absorption program & 7,000 & 21,000 \\
\hline Mettlet binnce program & 3,500 & 6,500 \\
\hline Subtotals & $\$ 63,500$ & 357,500 \\
\hline$\$ 121,000$ & & \\
\hline
\end{tabular}


Options 3 through 5 will incur an estimated additional $\$ 20,000$ to implement communications with the SFC system. This figure represents only a small fraction of the total costs that will be required to develop the entire laboratory management system. We assume that each EPA laboratory interested in developing a SFC system will budget a minimum of $\$ 20,000$ toward its development. The Office of Research and Development and the Management Information and Data Systems Division of the Office of Planning and Management are committed to fund a portion of the SFC development costs. Table B-4 summarizes the software costs for the five proposed optional automation systems.

Table B-4. Summary of mftware costs for the fre optional automation systems.

\begin{tabular}{lccccc}
\hline Software & Opton 1 & Option 2 & Option 3 & Option 4 & Option S \\
\hline Instrument applicutions progrims & No cost & No cost & No cost & No cost & $\$ 121,000$ \\
Communicktons with SFC & N/A & N/A & $\$ 20,000$ & $\$ 20,000$ & $\$ 20,000$ \\
\hline
\end{tabular}

Not applicable. 


\section{APPENDIX C}

\section{BENEFITS OF AUTOMATION}

To assess the benefits that will accrue to NEIC as a result of automation, we compare the manual effort required to meet the expected workload (Fig. 3) in each area to the effort we project will be required if automation is implemented. Effort is defined as the time reçuired for an employee to perform a task and is ex pressed as multiple and/or fractional full time employee, FTE.

\section{Instruinental Methods}

We have adopted a model to calculate the effective time required for a chemist to perform a determination by any of the candidate instrumeittal methods. The model considers the multiple tasks performed and includes factors for quality control samples, reruns, and samples that are diluted.

Combining the effective time with the assumed or projected number of determinations per year, one can calculate the total chemist time in effort (FTE) to handle the workload. The model is used to calculate the effort required using present manual techniques vs automated techniques.

The following equations are used in the model:

$$
t_{s}=p+(1+f)(\ell+i+c)+f d
$$

where

$t_{s}=$ total chemist time needed for each determination,

$\mathrm{p}=$ time for preparation of sample and log book per determination.

$f=$ time needed to $\log$ and introduce sample per determination,

$i=$ chemist time spent in operating the instrument per determination,

$c=$ time needed to calculate and transcribe results per dstermination,

$\mathrm{d}=$ time taken for djlution,

$f=$ factor for samples diluted.

In addition,

$$
e=t_{s} q r \frac{H}{H-T_{b}} \text {, }
$$

where

$e=$ the effective chemist time taken per determination,

$q=$ quality assurance factor,

$i=$ factor for samples retested,

$\mathbf{H}=$ time of a work session (the average length of time the instrument is operated for a work sessiun; for example, if the instrument is usually operated for a normal 8-hour day, $\mathrm{H}$ equals 8),

$T_{b}=$ time to set up instrument at the beginning of each work session, shut it down at the end, and run standards.

\section{Technicon Autoanalyzer}

It is projected that within two years approximately 3600 determinations per year will be performed by the Technicon AutoAnalyzer. Table C- 1 lists the tasks involved in the method and compares the effort that will be required by manual methods relative to the effort if automated techniques are adopted. 
Table C-1. Technicon AutoAnalyzer.

\begin{tabular}{|c|c|c|c|}
\hline \multirow[b]{2}{*}{ Task } & \multirow[b]{2}{*}{ Symbol } & \multicolumn{2}{|c|}{ Tìme, min } \\
\hline & & At present & Automated \\
\hline $\begin{array}{l}\text { Sample preparation } \\
\text { Log-in and introduction of sample } \\
\text { Opcration of instrument by chemist } \\
\text { Calculation and transcription of results } \\
\text { Ditution of off-scale samples } \\
\text { Factor for samples diluted }\end{array}$ & $\begin{array}{l}\text { p } \\
\mathbf{Q} \\
\mathbf{i} \\
\mathbf{c} \\
\mathbf{d} \\
\mathbf{f}\end{array}$ & $\begin{array}{l}3 \\
2 \\
2 \\
3 \\
5 \\
0.2\end{array}$ & $\begin{array}{l}3 \\
0.5 \\
0.5 \\
0 \\
5 \\
0.1\end{array}$ \\
\hline Calculated chemist time/determination & $t_{s}$ & 12.4 & 4.6 \\
\hline $\begin{array}{l}\text { Retest factor } \\
\text { Quality control factor } \\
\text { Serup and shutdown per work session } \\
\text { Hours per work session }\end{array}$ & $\begin{array}{l}\mathbf{r} \\
\mathbf{q} \\
\mathbf{T}_{\mathbf{b}} \\
\mathbf{H}\end{array}$ & $\begin{array}{c}1.1 \\
1.15 \\
60 \\
480\end{array}$ & $\begin{array}{c}1.1 \\
1.15 \\
60 \\
480\end{array}$ \\
\hline $\begin{array}{l}\text { Calculated effective chemist time per determination } \\
\text { Eenefit calculations }\end{array}$ & e & 17.9 & $\because 6.7$ \\
\hline $\begin{array}{l}\text { Number of determinations per day } \\
\text { Projected sample load per year } \\
\text { Chemist-days per year to meet load } \\
\text { Chemist-days per year (average) } \\
\text { Chemist-years (FTE) to meet load } \\
\text { Effort efficiency }=0.59-0.22=0.37 \text { FTE }\end{array}$ & & $\begin{array}{l}27 \\
3600 \\
133 \text { days } \\
225 \text { days } \\
0.59 \text { FTE }\end{array}$ & $\begin{array}{l}72 \\
3600 \\
50 \text { days } \\
225 \text { days } \\
0.22 \text { FTE }\end{array}$ \\
\hline
\end{tabular}

\section{Atomic Absorption Spectrophotometers}

We estimate that in two years approximately 3600 determinations per year will be performed by the atomic absorption spectrophotometer. Table C-2 gives a breakdown of the tasks involved in the method and a comparison of the effort that will be required by manual methods relative to the effort if automated techniques are adopted.

Table C-2. Atomic absorption spectrophotometry.

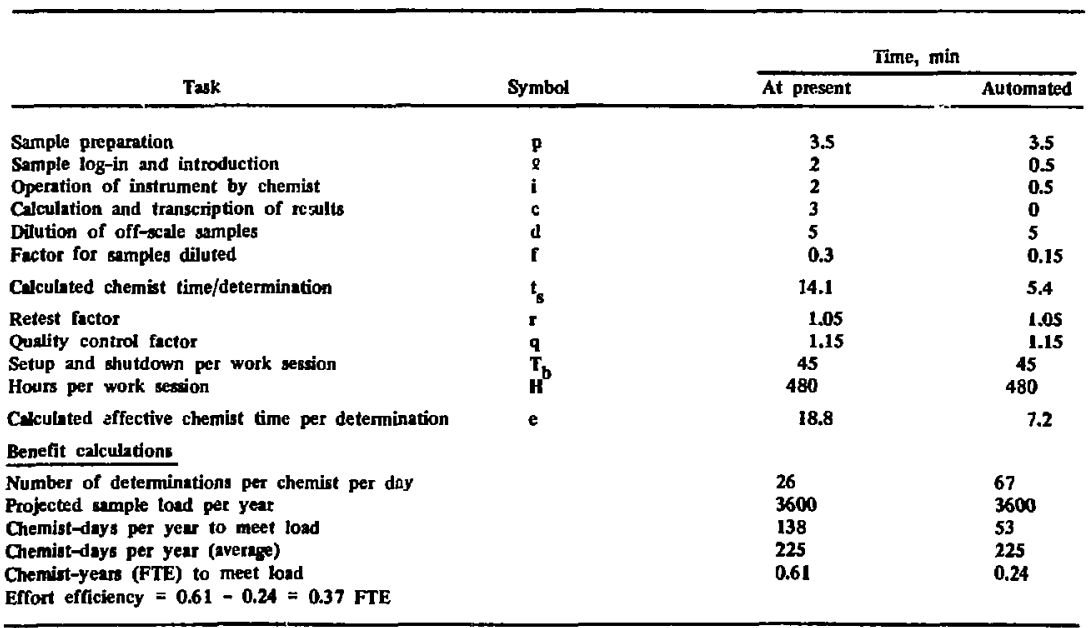


Table C-3. Electronic balance.

\begin{tabular}{|c|c|c|c|}
\hline \multirow[b]{2}{*}{ Task } & \multirow[b]{2}{*}{ Symbol } & \multicolumn{2}{|c|}{ Time, $\min$} \\
\hline & & At present & Aotomated \\
\hline $\begin{array}{l}\text { Sample preparation } \\
\text { Sample log-in and introduction } \\
\text { Operation of instroment by chemist } \\
\text { Colculation and transcription of resolts } \\
\text { Dilution of off-bcale } \\
\text { Factor for samples diluted }\end{array}$ & $\begin{array}{l}\mathbf{p} \\
\mathbf{q} \\
\mathbf{i} \\
\mathbf{c} \\
\mathbf{d} \\
\mathbf{f}\end{array}$ & $\begin{array}{l}10 \\
2 \\
1.5 \\
3.0 \\
- \\
-\end{array}$ & $\begin{array}{l}10 \\
1.5 \\
1.5 \\
0 \\
- \\
-\end{array}$ \\
\hline Calculated chemist time/detemination & $t_{s}$ & 16.5 & 13 \\
\hline $\begin{array}{l}\text { Relest factor } \\
\text { Quality control factor } \\
\text { Setup and shutdown per work session } \\
\text { Hours per work session }\end{array}$ & $\begin{array}{l}\mathbf{r} \\
\mathbf{q} \\
\mathbf{T}_{\mathbf{b}} \\
\mathbf{H}\end{array}$ & $\begin{array}{c}1.02 \\
1.10 \\
15 \\
480\end{array}$ & $\begin{array}{r}1.02 \\
1.10 \\
15 \\
480\end{array}$ \\
\hline $\begin{array}{l}\text { Calculated effective chemist time per determination } \\
\text { Benefit calculations }\end{array}$ & e & 19.1 & 15 \\
\hline $\begin{array}{l}\text { Number of determinations per chemist per day } \\
\text { Projected sample load per year } \\
\text { Chemist-days per year to meet load } \\
\text { Chemist-days per year (average) } \\
\text { Chemist-years (FTE) to meet load } \\
\text { Effort efriciency }=0.96-0.75=0.21 \text { FTE }\end{array}$ & & $\begin{array}{l}25 \\
5400 \\
216 \\
225 \\
0.96\end{array}$ & $\begin{array}{l}32 \\
5400 \\
169 \\
225 \\
0.75\end{array}$ \\
\hline
\end{tabular}

\section{Electronic Balance}

In two years approximately $5 \$ 00$ weighing determinations per year will be performed in the laboratory. This figure takes into consideration the workload changes that will be brought about by new methodology and added programs. Table C-3 gives a breakdown of the tasks involved in the method and a comparison of the effort that will be required if automated techniques are adopted.

\section{Quality Control}

During 1975, approximately $30 \%$ of the time of one staff chemist was devoted to quality control compliance. Table C-4 gives a breakdown of the tasks and a comparison of the present effort to that projected after automation.

Table C-4. Quality control.

\begin{tabular}{lcc}
\hline \multicolumn{1}{c}{ Task } & \multicolumn{2}{c}{ Time, min } \\
\cline { 2 - 3 } & At present & Automated \\
\hline $\begin{array}{l}\text { Statistical selection and } \\
\text { calculation of Shewhart } \\
\text { criteria }\end{array}$ & 0.15 & 0.05 \\
$\begin{array}{l}\text { Review of semple results } \\
\text { for compliance to } \\
\text { Shewhart limits }\end{array}$ & 0.15 & - \\
$\begin{array}{l}\text { Totals } \\
\text { Effort efrciency }=0.30-0.05=0.25 \mathrm{FTE}\end{array}$ \\
\hline
\end{tabular}




\section{Sample Management Tasks}

Administration and supervisory tasks, studies coordination, data collation and summary analyses reports are examples of management tasks. This study is concerned with those tasks that directly relate to operations of the analytical laboratory and analysis reports. It is the purpose of this study to determine which part of the general management effort is related to this latter category, the tasks that can be automated, and the benefits to be accrued.

During 1975 the management effort of the chemistry branch was determined to be 2.8 FTE, including the full time of the branch supervisor and secretary. $30 \%$ of the time of a project coordinator and $5 \%$ of the time of each of 10 chemistry branch staff people. In addition, it was determined that 2 FTE of the field operations branch performed management tasks directly related to chemistry analysis data. These tasks were described in the section Information and Data Flow, Chain of Custody, Records and Reports. The tasks involved include recalculating data and reformatting reports.

Table C-5 gives a breakdown of the management tasks and compares the present effort to the effort projected after automation. Table C-6 gives a summary of the benefits derived from Tables C-1 through C-5.

Table C-5. Management.

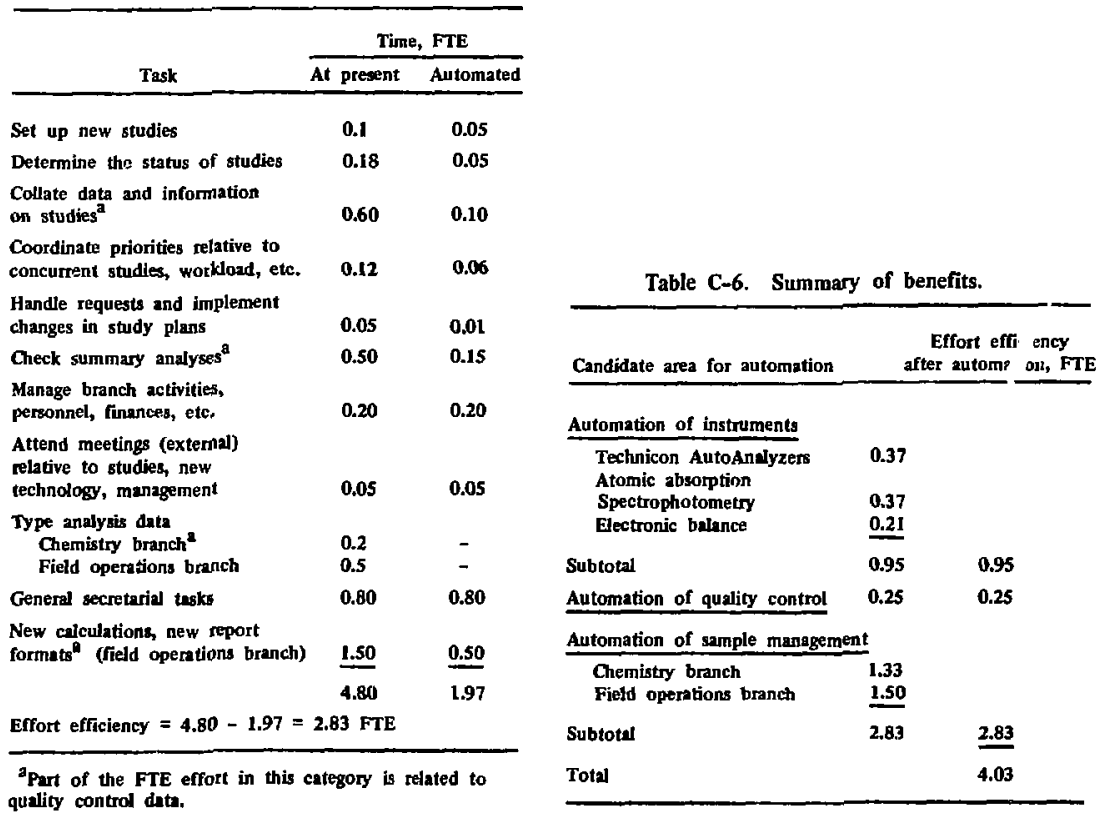




\section{APPENDIX D}

\section{DESCRIPTION AND BREAKDOWN OF ADDED OPERATING COSTS AS A RESULT OF AUTOMATION}

Each of the five proposed optional automation systems will add new costs to the annual operating costs of the laboratory. Included will be maintenance of computer hardware and peripherals, laboratory instrument hardware interfaces, and software. Those options that include communications with a SFC system will include additional costs for maintaining added computer hardware, software, and telephone communications.

Note that new skills and capabilities will be required by NEIC to implement and maintain an efficient automation system. The Environmental Research Center (ERC) in Cincinnati, has summarized these requirements, and they are included in Appendix $E$.

The ainual operating costs that reflect the above requirements for options $I$ and 2 are listed in Table D-1; Table D-2 lists the requirements for options 3 through 5.

Table D-1. Annual operating costs for options 1 and 2 .

\begin{tabular}{llr}
\hline \multicolumn{1}{c}{ Category } & Option 1 & Option 2 \\
\hline $\begin{array}{l}\text { Maintenance of the computer } \\
\text { hardware and peripherais } \\
\text { (vendor supplied) }\end{array}$ & $\$ 10,000^{2}$ & $\$ 9,500^{b}$ \\
$\begin{array}{l}\text { In-house maintenance of } \\
\text { interface hardware and } \\
\text { software }\end{array}$ & $\$ 20,000^{\mathrm{c}}$ & $\$ 20,000$ \\
\hline
\end{tabular}

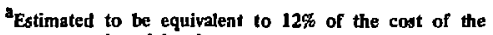
computer and peripherals.

b The cost of the NOVA 840 system (original computer and peripherals plus additions shown in Table B-1) is estimated to be $\$ 78,500$. The maintenance cost is based on $12 \%$ of this estimate.

cApproximately one-half of the time of a full time employe (0.5 FTE) with the skills described in Appendix $\mathrm{E}$ is recommended.
}

Table D-2. Annual operating costs for options 3 through 5.

\begin{tabular}{|c|c|c|c|}
\hline Category & Option 3 & Option 4 & Option 5 \\
\hline $\begin{array}{l}\text { Maintenance of the computer hardware and peripherals } \\
\text { (vendor supplled) }\end{array}$ & $\$ 14,400$ & $\$ 13,700^{b}$ & $\$ 21,700$ \\
\hline $\begin{array}{l}\text { In-house maintenance of interface handwate and software } \\
\text { including communications with SFC }\end{array}$ & 60,000 & 60,000 & 60,000 \\
\hline Eutimated annual costs for telephone communications ${ }^{d}$ & $\$ 4,000$ & $\$ 4,000$ & $\$ 4,000$ \\
\hline
\end{tabular}

\footnotetext{
Estimated to be equivilent to $12 \%$ of the cost of the computer and peripherals.

bhe cost of the NOVA 840 system (original computer and peripherals plus additions shown in Table B-1) is estimated to be $\$ 114,(60 C$. The maintenance cost is bused on $12 \%$ of this estimate.

${ }^{C}{ }_{A}$ tots of 1.0 full time employee (FTE) with the shill described in Appendix $E$ is recommended. The additional 0.5 FTE relative to optons 1 and 2 is requined for msintemance of communications with SFC.

Annual telephone communication costs include the following: Modem, Bell series (4800 baud): $\$ 2,400 / y$; Telephone line; $\$ 300 / y$; FTS Charge: $\$ 2,300 / y$. These represent combined costs for both ends of the link.
} 


\section{APPENDIX E}

\section{NEW PERSONNEL SKILLS AND CAPABILITIES RECOMMENDED FOR THE AUTOMATED LABORATORY*}

The purpose of this appendix is to provide the management of a prospective automated laboratory with a concise description of new skills and capabilities required so that planning and implementation in the areas of training, manpower allocation, and (if necessary) hiring may be conducted betore the system is installed. This appendix is also designed to serve as an operational policy cornerstone for client-ERC-LLL-vendor maintenance relationships.

The new functions and responsibilities in an automated laboratory are divided into two broad areas: laboratory activities, and computer system maintenance. The two areas require different personnel skills and capabilities. Within the laboratory the following fiactional subdivisions exist:

- The system is used to process analytical samples. For example, a dialogue is conducted with the computer as it executes the instrument control and data acquisition/manipulation programs.

- Programs are modified as required, to tailor them to the specific needs of the laboratory. Modifications by the laboratory scientist are limited to changes in the basic programs in such areas as output report format, dala reduction procedures, etc.

Computer maintenance is subdivided as follows:

- Hardware maintenance and upgrades, including handling the computer vendor's service contract, as well as responsibility for maintaining the custom electronics hardware. These skills are detailed below.

- Instrument control and applications software maintenance and upgrades (if any), including assisting the laboratory scientist to modify programs as described.

To use an automated laboratory system, the laboratory scientist must interact with the computer. He enters data and control information in response to computer queries and prompts. This is done at the typewriter terminal located near the instrument. The analyst must modify his previous manual analytical procedures and methods somewhat to accommodate this new "man-machine dialogue." He should be awate of necessary actions when an abnormal condition arises, for example, if he types in the wrong thing, injects the wrong sample, or the computer detects or causes some sort of error. As he becomes more familiar with the system, the laboratory scientist should be able to spot and correct human, instrument, or computer malfunctions quickly himself, and then present the symptoms of more involved problems to the systems maintenance person for action. The laboratory scientist acquires these skills in several ways:

- Working visits to ERC/Cincinnati for tutorial instruction before the system is delivered. Instruction includes observation and use of a similar automated instrument or procedure, under the guidance of a scientist who is already using these skills.

- Remote access to an existing lab system computer (via dial-up terminal) to learn the basic language and instrument program dialogues.

- Tutorial sessions given by the automation installation team while the system is being installed.

- Self study of procedures manuals provided with the system for the use of each instrument and facility.

As the laboratory scientist becomes more familiar with the use of the system he will probably want to modify and extend the capabilities of the BASIC applications software. He may want to streamline the instrument setup and operation dialogue once he has gained familiarity with the inputs that the system needs to carry out his analyses. (Example: Shorten "ENTER NUMBER OF SPIKED SAMPLES" to "SPIKES?")

He will want to convert runtime options (provided with the delivered system) to program constants to save time, in the event that the inputs do not need to be changed during a normal run in the future. (Example: Remove variable input prompt: "SPIKES?" above, altogether, and convert it to a program constant.)

He may want to change the instrument data reduction algorithm to accommodate a special data analysis requirement or to implement a new analysis method. He may also want to change the structure, content, or appearance of an output report.

To make these changes, the analyst must spend some time learning additional details of the basic language interpreter as well as the specifics of the structure and operation of the basic program. The depth of knowledge required depends, of course, on the degree of program modification desired. Again, informal

\footnotetext{
"Bruce P. Almich, Environmental Research Center (ERC) Cincinnati, Ohio.
} 
Table E-1. New skills required of the analyst.

\begin{tabular}{|c|c|}
\hline Skilt & Time/required resourecs \\
\hline $\begin{array}{l}\text { Leaming how to use the } \\
\text { system as Jclivered } \\
\text { (tutorial course given at } \\
\text { installation time). }\end{array}$ & 1 manl-wk/analyst \\
\hline $\begin{array}{l}\text { Learning how to spot and } \\
\text { correct malfunctions. }\end{array}$ & First two months of use \\
\hline $\begin{array}{l}\text { Predelivery orientation } \\
\text { (dial-up or travel to } \\
\text { ERC/Cincinnsti). }\end{array}$ & 3 man-days/analyst \\
\hline $\begin{array}{l}\text { Introductory course/study } \\
\text { in BASIC.? }\end{array}$ & 1 man-wk/analyst \\
\hline $\begin{array}{l}\text { Advanced topics in BASIC } \\
\text { (required for extensive } \\
\text { program modifications). }\end{array}$ & 1 man-wk/analyst \\
\hline $\begin{array}{l}\text { Training or self study in } \\
\text { program structure (making } \\
\text { full use of the system). }\end{array}$ & $\begin{array}{l}\text { Leamed during first } \\
9 \text { mo of opemation, by } \\
\text { motivated users }\end{array}$ \\
\hline
\end{tabular}

${ }^{a}$ optional.

coursework and study ure required. For the benefit of everyone involved, the analyst should also learn how to produce good documentation for the programming changes he makes in the delivered basic code. He should make every effort to keep the documentation for the automated operation of his instrument current and accurate. He assumes local software support responsibility for any programs in which he substantially modifies the disk file or the operational logic structure. Local responsibility is also assumed for local post-delivery modifications to the sample-file control interface, because a single agency-wide SFC may exist in the future.

For each analyst, new skills are required to interact with the computer in performing laboratory analyses. No programming training or knowledge is required for the elementary skills. It is necessary to acquire programming skills in the basic language if the analyst wishes to modify basic language applications software. This language is the most simple and fexible general programming facility available. It is typically taught to high sehool students in mathematics classes and is also required in most technical undergraduate and graduate university degree programs. Our experience indicates that the operational instrument dialogues are easily learned. In addition. EPA laboratory personnel are, to a degree, modifying and enhancing the delivered basic programs. Table E-1 summarizes the above discussion, in terms of milestones and estimated resource requirements for training.

The analyst must aiso learn to maintain the overall laboratory automation system as a collection of hardware and software elements, including instruments, interfaces, computers, and programs. For convenience, the term "in-house maintenance person" is defined as a composite for the skills and capabilities required in this area, althougt se skills may be either concentrated in one or two people or shared among several in an actual laborato. situation.

Theie are two types of software; the system-NOVA/ECLIPSE assembly language, vendor supplied (Data General Corp.), and LLL/EPA developed; and system applications-standard high level languages, BASIC interpreter code for instrument automation and data reduction.

There are three types of hardware: the computer (maintained under service contract at a cost of $\$ 1,000$ per month); custom (LLL/EPA designed and developed), including terminals, cables, connectors, instrument interfaces, computer interfaces, etc; and laboratory instruments (e.g., Technicon AutoAnalyzer, Perkin/Elmer $A A$, etc.).

The primary responsibility of the maintenance person is to keep the various hardware and software elements in full working order with preventive and remedial maintenance as well as hardware and software up* grades, as required. Preventive maintenance consists of the following: 
- Monitor the computer hardware maintenance contract and ensure that the computer receives its monthly preventavive maintenance service from Data General, as provided in the contract. Keep Data General appraised of problem areas with the equipment.

- Periodic inspection (for example, offline testing and observing production operation) of the custom and laboratory instrument hardware to ascertain proper operation.

- Periodic backups and library maintenance of all software disk files. Backups should be in triplicate on magnetic tape, with an index to locate disk file images on the tape. A backup should be made of the affected program and data files whenever a net investment (or replacement cost) of effort in these files exceeds an average of four hours of work per laboratory analyst or computer programmer.

Remedial maintenance is required when something breaks, whereas preventive maintenance minimizes frequency, losses, and restoration costs of unforeseen breakage. In-house remedial maintenance skills are required to successfully complete the following sequence of tasks whenever something breaks:

- Identify symptoms and find out which instruments, users, and system operating functions are affected.

- Isolate the problem to the subsystem level, for example to one of the three types of hardware in the system.

- If the problem is in a laboratory instrument, initiate repairs in-house, by contract, or by out-ofcontract extramural service repairs. (It is extremely important to have minimum administrative delays in placing service procurements with established, reputable service organizations.)

- If the problem is in the custom EPA/LLL hardware, initiate in-house repairs. Begin by installing working spares at the plug-in module level. (Note: the client lab should have a full complement of replaceable spare parts for all custom hardware on site. This is recommended to all clients who do not have ready access to a large electronics and mechanical hardware stockpile.) If difficulty is encountered in this process, ERC/Cincinnati or LLL through ERC can provide assistance. ERC will provide a list of recommended tools and troubleshooting/repair equipment, if requested.

If the problem is in the computer, two determinations must be made next: the problem must be identified as a hardware or software problern; or, the problem must be identified as a "Data General" problem or a "Non Data General" problem. Lack of caution here can result in a premature commitment to expensive outof-contract vendor service.

Generally, if the problem is in the computer hardware and is present when either Data General diagnostic or unmodified Data General system software is running (with the LLL custom hardware interface board removed), Data General may be called in for free in-contract repairs. If the problem is in the agency-wide supported version of the opertional software, a second client lab or ERC/Cincinnati may be called for immediate consultation, and if necessary, assistance. In the absence of local resources, all other cases are handled on an individual basis; in these cases, the client lat and its local resources are responsible for solving the problem. In-house hardware repairs and modifications should not be made on Data General hardware. Other electronic repairs should be conducted at the module/board replacement level. Parts lists and availability information for custom electronic and mechanical hardware should be kept in good order.

Agency-wide support (that is, all support external to the client lab) is available for all hardware and software as delivered and made operational by the installation team, as well as for all agency-wide supported upgrades.

Depending on the nature and extent of post-installation modification to the delivered system and the adherence to agency-wide upgrades, post delivery support levels from all sources external to the client laboratory will vary. Generally speaking, "if you change it, you support it, even if the person who changes it goes away." Undocumented changes cannot be supported by anyone. The Data General service contract with GSA is a handy reference in this area.

The maintenance person must also assist laboratory staff in making viable changes and additions to the delivered package of applications software. Present changes are limited to the basic instrument programs and communications with the sample file control system. In an operational situation, the maintenance person has historically assumed the role of instructor and consultant to the laboratory scientist and performs the training previously described.

Finally, the maintenance person must install and test hardware and software upgrades. An upgrade occurs in one of the following circumstances. If the client laboratory determines a need for additional hardware or software not on the "agency-wide support" list, the lab can take responsibility for designing, obtaining approval for, and implementing the new facility. This can be a very involved and complex process, especially in 
the areas of system software modification and obtaining headquarters approvals. If a proposed upgrade is determined to be applicable agency-wide, it can be implemented. In these cases, a system design is performed, approvals are secured, and it is implemented with the assistance of ERC/Cincinnati. This is the preferred procedure for adding a new instrument to the system. An ongoing example of this is the agency-wide maintenance of the Data General systems software subscription service, distributed by ERC/Cincinnati and installed as appropriate in all laboratory automation sites.

Some systems level upgrades are required on all machines to ex:end performance, fix system bugs, and ensure applications software transportability. These are easily performed at the client site because the maintenance person need only be able to use the Data General operating system command language and the text editor. More complicated upgrades in software may be handled by directly loading a client computer with operating software via telecommunications with the ERC/Cincinnati facilities.

How will the maintenance person be trained to provide these services to the laboratory? With the purchase of a Data General computer system, the customer is entitled to two weeks of free training credits at one of two Data General training centers in the U.S. Two-to-four weeks of training are essential for preferably two laboratory people before the system is delivered. Each person should have one week of training in Data General operating system concepts and facilities, and one week in either assembly programming, FORTRAN programming, or hardware maintenance overview. This training is desireable so the laboratory can maintain service continuity in the case of absenteeism or a job change by the trained in-house maintenance person.

Each maintenance person should spend a minimum of one week of predelivery orientation training at a working laboratory facility elsewhere in the agency. Five-to-eight working days at ERC/Cincinnati would be optimum.

Each maintenance person should participate actively in the installation and delivery testing of the system; and an additional week of training should be given to the installation team members at delivery time. We estimate about six months of operation are required for the analyst to become completely familiar with his duties.

In conclusion, we have provided the prospective client lahoratory with the above description of new personnel skills required to use the new automation system, by describing functions and responsibilities in two broad areas. The first area represents a reallocation of existing personnel within the laboratory. The second area can b: staffed in one of the following ways:

- One or two existing laboratory people can be trained and reassigned to perform the functions, as did Region Five, with no additional personnel required. This would be especially appropriate in a small-tomedium laboratory with modest post-delivery modification needs. The people could be selected from those chemists with some computer background, or an existing in-house person with electronics and some high level language programming background.

- A new chemist or electronics technican with some previous computer background could be hired. Background in electronics equipment service and repair and BASIC/FORTRAN programming is extremely valuable. This is the ' cost appropriate course of action for the large production laboratories with sincere interest in proper system utilization and upgrades.

- These two methods can be combined to form a working team of "principal automation chemist" and system maintenance person, which seems like a very desirable concept for a lab engaged in large sample volume production and significant enhancements.

- A computer person can be hired whose primary cmphasis would be software maintenance and ennancement. He would work with staff members familiar with the system. Hardware maintenance could be performed with additional extramural assistance.

With any of the above alternatives, it is estimated that the first broad skills area should require no new hiring. The minimum requirement for the second skills area is no new hiring, in a lab environment of well motivated in-house chemists with previous computer backgrounds, and few wishes for enhancements. The most probable situation would be hiring one new chemist or engineer/technican for the minimum support level by the maintenance person of 0.5 man-yr $/ y r$. The naximum new personnel requirement would be 2.0 man-yr/yr, which would result in full in-house hardware, and instrument/ERC software support, maintenance, and upgrades. In this cost/benefit analysis, 1.0 man-yr/yr has been allocated to the system function for the recommended system. ERC/Cincinnati is available to consult on these matters. 